\title{
Preliminary Aerodynamic and Aerothermodynamic Assessment of the VTO Hopper Booster
}

\author{
Giuseppe Pezzella \\ Fluid Dynamics Laboratory, Aerothermodynamics Division, Italian Aerospace Research Centre-CIRA, via Maiorise, \\ I-81043 Capua, Italy \\ Correspondence should be addressed to Giuseppe Pezzella, g.pezzella@cira.it
}

Received 12 January 2011; Accepted 1 March 2011

Academic Editors: C. J. Kähler, k. Mekheimer, F. Mendez, T. Uchiyama, B. Yu, and Z. Yu

Copyright ( 2011 Giuseppe Pezzella. This is an open access article distributed under the Creative Commons Attribution License, which permits unrestricted use, distribution, and reproduction in any medium, provided the original work is properly cited.

\begin{abstract}
Within the framework of the Future Launchers Preparatory Program, carried out by the European Space Agency, the VTO-Hopper reusable launcher is investigated. This concept is a winged sub orbital vehicle designed for vertical take-off with an expendable upper stage, able to deliver a payload up to $8 \mathrm{Mg}$ in geostationary transfer orbit. After the staging, the reusable booster will reenter the Earth's atmosphere, and then perform a downrange landing. In this paper the current design activities are described. The goal has been to define the preliminary booster aerodynamic and aerothermodynamic databases. Therefore, the aerothermal environment that the vehicle will encounter along its lifting reentry has been provided and analyzed. Different design approaches have been addressed. In fact, aerodynamic and aerothermodynamic analyses have been performed by using both engineering and numerical methods. For instance, a 3D Panel Methods code, typical for hypersonics, has been employed; the heat flux distributions have been evaluated by means of improved boundary layer methods. Increasing the order of complexity, a number of detailed 3D CFD analyses have been performed for different flight conditions along the descent trajectory. Results show that the aerodynamics and aerothermodynamics derived from engineering design approach are valid only for preliminary analysis purposes.
\end{abstract}

\section{Introduction}

This paper describes the aerodynamic and aerothermodynamic preliminary design activities for the SOH-VTO Hopper concept performed in the frame of the European Space Agency (ESA) Future Launcher Preparatory Program (FLPP). This program is finalized to prepare Europe for the decision on the development of a Next Generation Launcher (NGL) within the next decades $[1,2]$. The reentry scenario with the corresponding loading environment for the proposed vehicle concept is reported and analyzed. The hypersonic aerothermal characteristics of Hopper VTO are investigated with a trajectory-based design approach by means of several engineering and CFD analyses [3, 4]. Being a phase 0 design, the air is modelled as a perfect gas and the more detailed analyses have been based on laminar flow conditions only. Results show that the aerodynamics derived from engineering design approach is sufficiently accurate for preliminary analysis purpose; moreover, surface heat loads have been computed on the vehicle configuration for thermal shield design scopes. The final results that will be applicable for the prosecution of the activity of FLPP program carried out by ESA are then summarized.

\section{VTO Hopper Concept}

The VTO Hopper is one of the possible future launch systems investigated in the frame of FLPP program $[1,2]$. The vehicle architecture is shown in Figure 1. The VTO launch vehicle is a two-stage space transportation system made up of a fully reusable first stage and an expendable upper stage, (see Figure 1(a)). The vehicle lifts off vertically from Guyana Space Centre (GSC) and performs a parabolic suborbital trajectory; after $\operatorname{MECO}(h>90 \mathrm{~km}, v>5 \mathrm{~km} / \mathrm{s})$, the upper stage separates from the reusable booster, ignites, and transports the payload into the final target orbit. The reference mission for FLPP 1.2 consists of the injection of a $8 \mathrm{Mg}$ payload into geostationary transfer orbit (GTO).

After separation from the payload, the reusable booster is designed to perform an unpowered ballistic arc, followed by a gliding downrange reentry flight to a landing site 


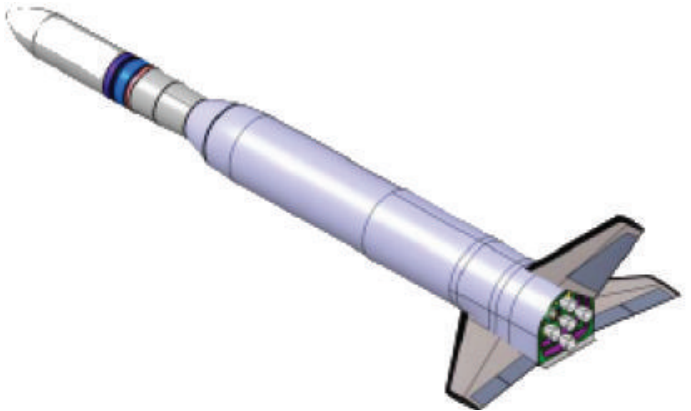

(a)

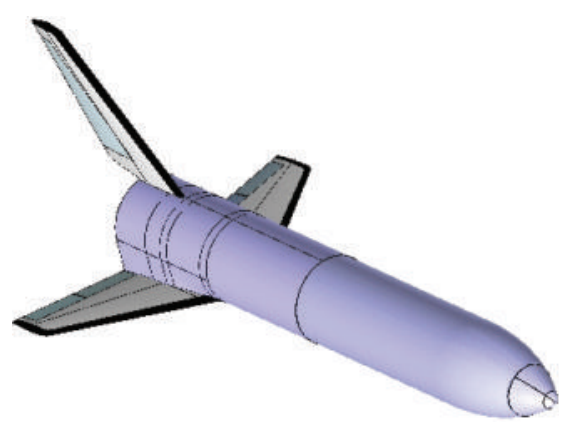

(b)

FIGURE 1: SOH-VTO Hopper configuration: (a) Complete vehicle and (b) reusable stage.

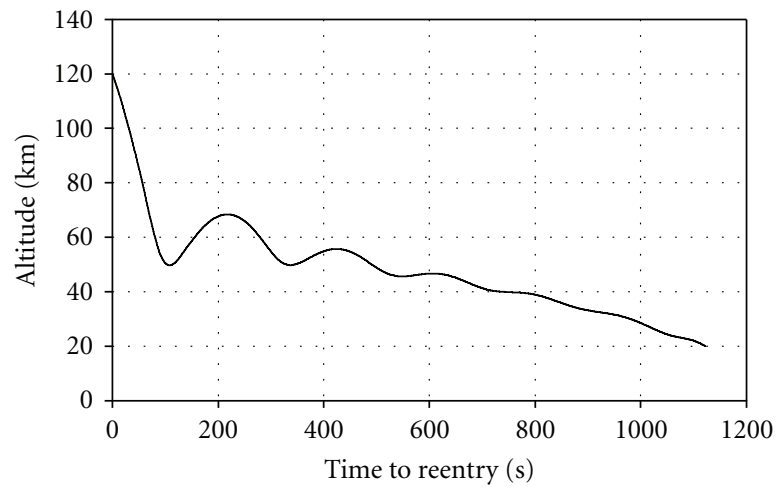

(a)

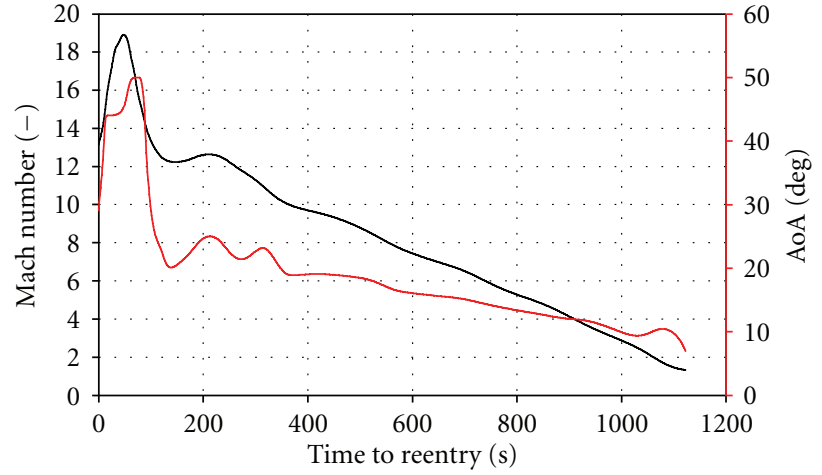

Mach number AoA

FIgURE 2: VTO Hopper reentry trajectory profiles: Altitude versus time (a) and Mach/AoA versus time (b).

$4500 \mathrm{~km}$ far from the launch site. The booster is designed to land horizontally. The current vehicle shape features a body fuselage with a circular cross section, wings in rear position, and a vertical fin. The circular shape has been adapted in order to introduce the body flap.

\section{VTO Hopper Nominal Reentry Flight Scenario}

The investigated reentry scenario for the VTO Hopper launcher is summarized in the following Figures 2 and 3 . Figure 2 shows the altitude versus reentry time from the entry interface (e.g., $120 \mathrm{Km}$ ) to terminal area energy management (TAEM), while on the right side, the Mach and AoA profiles versus the reentry time are reported. Figure 3 reports the flight profile in terms of altitude-velocity map. The constant Mach and Reynolds numbers lines are included in the figure in order to characterize the aerodynamic flight scenario of the launcher.

Several Mach numbers ranging from 2 to 20 and five Reynolds numbers (i.e., $[1,3,8,20,70] \times 10^{6}$ ) with respect to vehicle's $L_{\text {ref }}$ have been considered for the simulations as

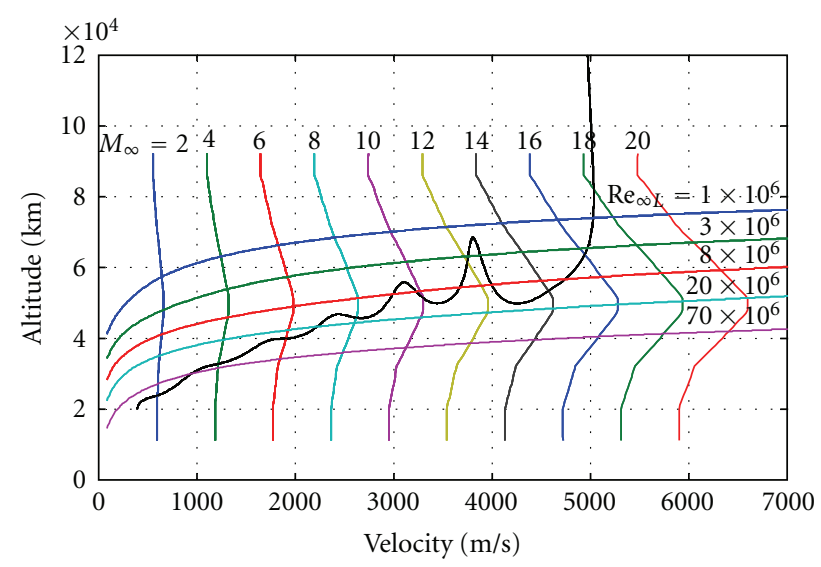

Figure 3: SOH-VTO Hopper reentry trajectory. Altitude-velocity map.

displayed in Figure 3. It must be noted that the ranges of Mach and Reynolds numbers have been selected to cover a wide part of the reentry flight, especially the most critical one from the aeroheating point of view (i.e., $M_{\infty}=13.4$ ). 


\section{Description of Design}

A summary review of the aerodynamic and aerothermodynamic characteristics of the VTO Hopper concept is performed. These evaluations have been aimed at carrying out only a preliminary aerodynamic database (AEDB) and aerothermodynamic database (ATDB) for such configuration, in compliance with the phase-0 design level. The range between Mach 2 and Mach 20 has been analyzed, with the goal to provide aerodynamic database for flight mechanics analyses, and wall heat fluxes for TPS sizing activities. The aerodynamic coefficients have been provided as a function of Mach number and angle of attack (zero sideslip angle and no active control surface deflections) according to the "spacebased" design approach $[3,4]$.

On the other hand, the heat fluxes have been computed for a number of selected points along the vehicle reentry trajectory, as prescribed by the "trajectory-based" design approach $[3,4]$. The first one (AEDB) dictates the generation of a complete data set as function of a number of independent parameters (i.e., $M_{\infty}, \operatorname{Re}_{\infty}, \alpha$ ); the second one (ATDB) consists in performing the aerothermal computations at a finite number of "critical" points on a given nominal design trajectory. In both cases, by using an engineering-based design tool, one can rapidly develop both aerodynamic and aerothermodynamic databases as a function of the freestream parameters in a matter of hours.

In the present analysis, only continuum regime (supersonic and hypersonic speed ranges) with the air modeled as perfect gas has been studied. It is worth to underline, however, that at high altitudes the rarefaction and real gas effects should be taken into account when the vehicle is flying at high Mach number, since they strongly affect both vehicle AEDB and ATDB. Therefore, these aspects would have to be considered for next phases of vehicle design. In the following paragraph, the tools used for the analysis are described.

4.1. Aerodynamic and Aerothermodynamic Analysis Tools. The VTO-Hopper experiences a number of severe flight conditions for which analyses are required. It must return from orbit, fly trimmed throughout hypersonic and supersonic regimes until landing, and withstand severe aeroheating. An accurate aerodynamic and aerothermodynamic analysis of all these flight conditions is very complex and timeconsuming, and not compatible with a phase 0 design study, for which fast predicting methods are requested. Therefore, the evaluations of the vehicle AEDB and of its reentry aerothermal environment have been mainly performed by means of engineering tools, while a limited number of accurate CFD computations have been carried out in order to verify the attained accuracy, and to focus on some critical design aspects not predictable with simplified tools.

Engineering-based aerodynamic and aerothermodynamic analyses have been extensively performed by using a 3D Panel Methods code, namely, SIM (Surface Impact Method), developed by CIRA in the frame of its research activities on preliminary design of reentry vehicles. This tool, at high supersonic and hypersonic speeds is able to accomplish the aerodynamic and aerothermodynamic analyses of a

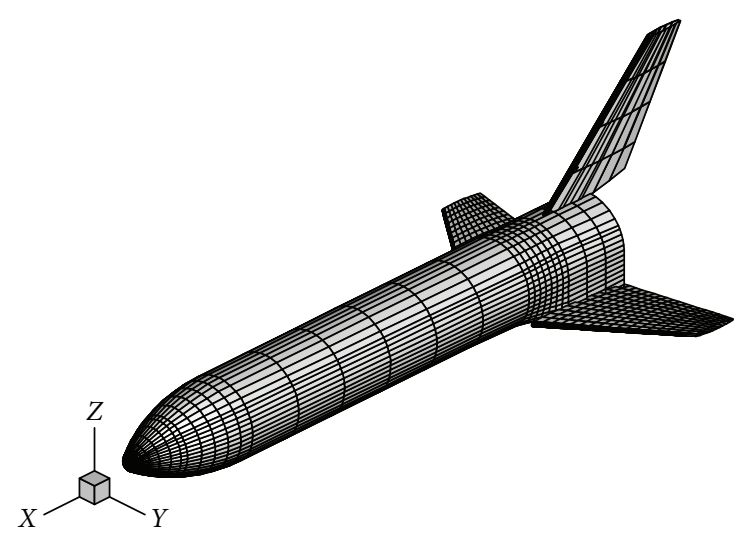

FIGURE 4: Launcher's surface mesh used for engineering analyses.

complex reentry vehicle configuration by using simplified approaches as local surface inclination methods and approximate boundary-layer methods, respectively. Surface Impact Methods (SIM) typical of hypersonics are based on Newtonian, Modified Newtonian, Tangent Cone, and Tangent Wedge theories. The heat flux calculations have been performed using both CIRA engineering code and simplified engineering formulas in order to confirm and integrate the tool results (e.g., heat loads) at the most critical parts of the vehicle such as vehicle nose and wing leading edges. The CIRA engineering code performs the aerothermal analysis of the vehicle configurations based on the surface streamlines. The streamlines are generated starting from the inviscid surface velocities generated previously by the code, in the aerodynamic analysis phase. Once the streamlines are obtained, the aeroheating analysis is performed along each streamline by using a simple one-dimensional boundary layer method. The generic vehicle component may be modeled as either a flat plate or a leading edge by selecting the appropriate boundary layer model. In Figure 4, a typical mesh surface of the VTO, used for the engineering level computations, is shown.

On the other hand, the numerical code used to carry out the CFD analyses of the SOH-VTO vehicle is the CIRA code H3NS. It solves the flow-field governing equations, including chemical and vibrational nonequilibrium, with a finite volume approach; a flux difference splitting upwind scheme is used for the convective terms, with a secondorder ENO-like reconstruction of cell interface values. The viscous fluxes are calculated by central differencing, that is, computing the gradients of flow variables at cell interfaces by means of Gauss theorem. Time integration is performed by employing an Euler Forward scheme coupled with a point implicit treatment of the species and vibration energy source terms. Both sequential and parallel versions of the code are currently available. Several boundary conditions can be applied for the viscous computations, including different catalycity models and the possibility to assign a fixed temperature or a radiative equilibrium condition at the wall. CFD computations have been carried out on a multiblock structured grid (shown in Figure 5). The grid 


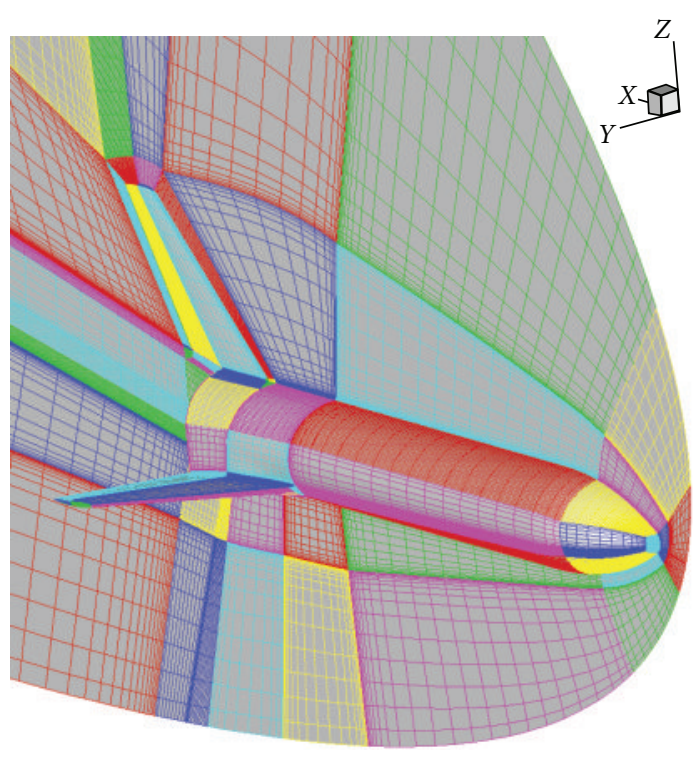

(a)

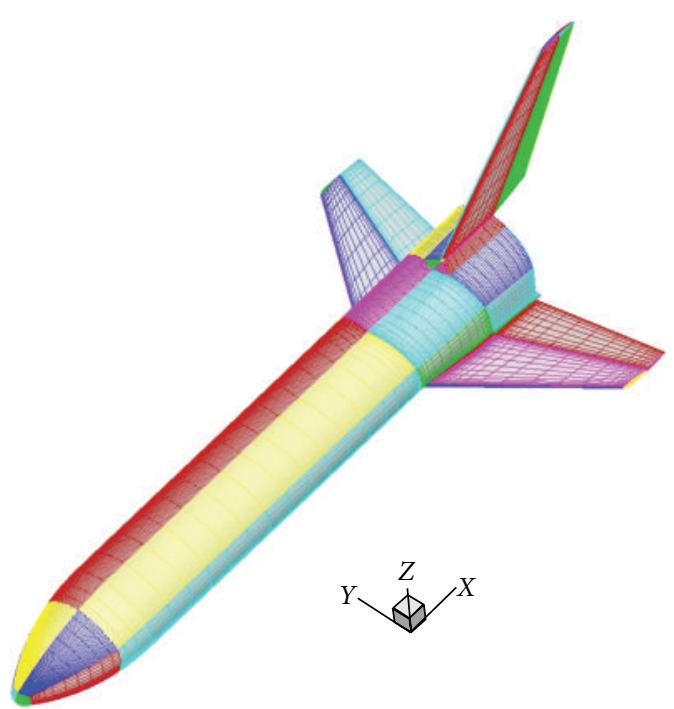

(b)

FIGURE 5: Multiblock CFD domain. Mesh on symmetry plane and vehicle surface.

TABLE 1: Design point freestream conditions for which the heat fluxes have been computed.

\begin{tabular}{lccc}
\hline Control points & $H(\mathrm{kM})$ & $M(-)$ & AoA $(\mathrm{deg})$ \\
\hline No. 1 & 81.1 & 18.6 & $47.7^{\circ}$ \\
No. 2 & 50.8 & 13.4 & $29.7^{\circ}$ \\
No. 3 & 68.3 & 12.6 & $24.8^{\circ}$ \\
No. 4 & 50.0 & 10.6 & $22.3^{\circ}$ \\
No. 5 & 46.5 & 8.5 & $18.0^{\circ}$ \\
\hline
\end{tabular}

used for Euler calculations has consisted of 62 blocks for an overall number of 829.000 cells (half body). The grid is tailored for the free-stream conditions of the trajectory check points, summarized in Table 1 hereafter.

The distribution of surface grid points has been dictated by the level of resolution desired in various areas of vehicle such as stagnation region and base fillet, according to the computational scopes. A close-up view of $3 \mathrm{D}$ mesh on the vehicle surface can be seen on the right side of Figure 5. Grid refinement in strong gradient regions of flow field has been made through a solution adaptive approach.

\section{VTO Hopper Aerodynamic Analysis}

5.1. Aerodynamic Features of VTO Hopper. The VTO Hopper launcher features a rather conventional slender missile-like vehicle (see Figure 1) with a small delta planform wing (45.17 $7^{\circ}$ leading edge sweep) in rear position and a central vertical stabilizer, as basic shape. The concept shows a circular cross section with a loft fillet on the belly side to accommodate the wing (blended wing body interface). The aerodynamic controls comprise rudders on the vertical tail, elevons and ailerons on the wings, and a body flap underneath the main engines in order to provide maneuverability and longitudinal stability during the atmospheric descent. Normalizing the vehicle overall dimensions by fuselage length $\left(L_{\text {ref }}=58.8 \mathrm{~m}\right)$, the SOH-VTO Hopper is characterized by the following normalized reference data: $B^{\prime}$ $($ wing span $)=0.54, S^{\prime}($ reference surface $)=0.056, X_{\mathrm{MRP}}^{\prime}=$ $0.69, Y_{\mathrm{MRP}}^{\prime}=0, Z_{\mathrm{MRP}}^{\prime}=0$. In the following, the aerodynamic analysis is shown in terms of lift $\left(C_{L}\right), \operatorname{drag}\left(C_{D}\right)$, and pitching moment $\left(C_{\mathrm{My}}\right)$ coefficients which are calculated according to (1) and (2), respectively.

$$
\begin{gathered}
C_{i}=\frac{F_{i}}{(1 / 2) \rho_{\infty} v_{\infty}^{2} S_{\mathrm{ref}}}, \quad i=L, D, \\
C_{M j}=\frac{M_{j}}{(1 / 2) \rho_{\infty} v_{\infty}^{2} L_{\mathrm{ref}} S_{\mathrm{ref}}}, \quad j=Y .
\end{gathered}
$$

5.2. General Inputs for Aerodynamic Data Set Generation. For the VTO Hopper configuration, the following reference parameters have been chosen in order to obtain aerodynamic forces and moments nondimensional coefficients (see Figure 6(a)): $L_{\text {ref }}=58.8 \mathrm{~m}$ (longitudinal reference length); $S_{\text {ref }}=193.23 \mathrm{~m}^{2}$; Pole coordinates are $(0,0,0) \mathrm{m}$ (e.g., vehicle nose). Starting from the reentry flight scenario summarized in Figure 3, the aerodynamic data set has been generated for the following ranges:
(1) $2<M<20[2,3,5,7,10,15,20]$;
(2) $0^{\circ}<\alpha<50^{\circ}[0,5,10,15,20,25,30,35,40,45,50]$;
(3) $10^{6}<\operatorname{Re}<70 \times 10^{6}[1,3,8,20,70] \times 10^{6}$;
(4) $\beta=0^{\circ}$. 


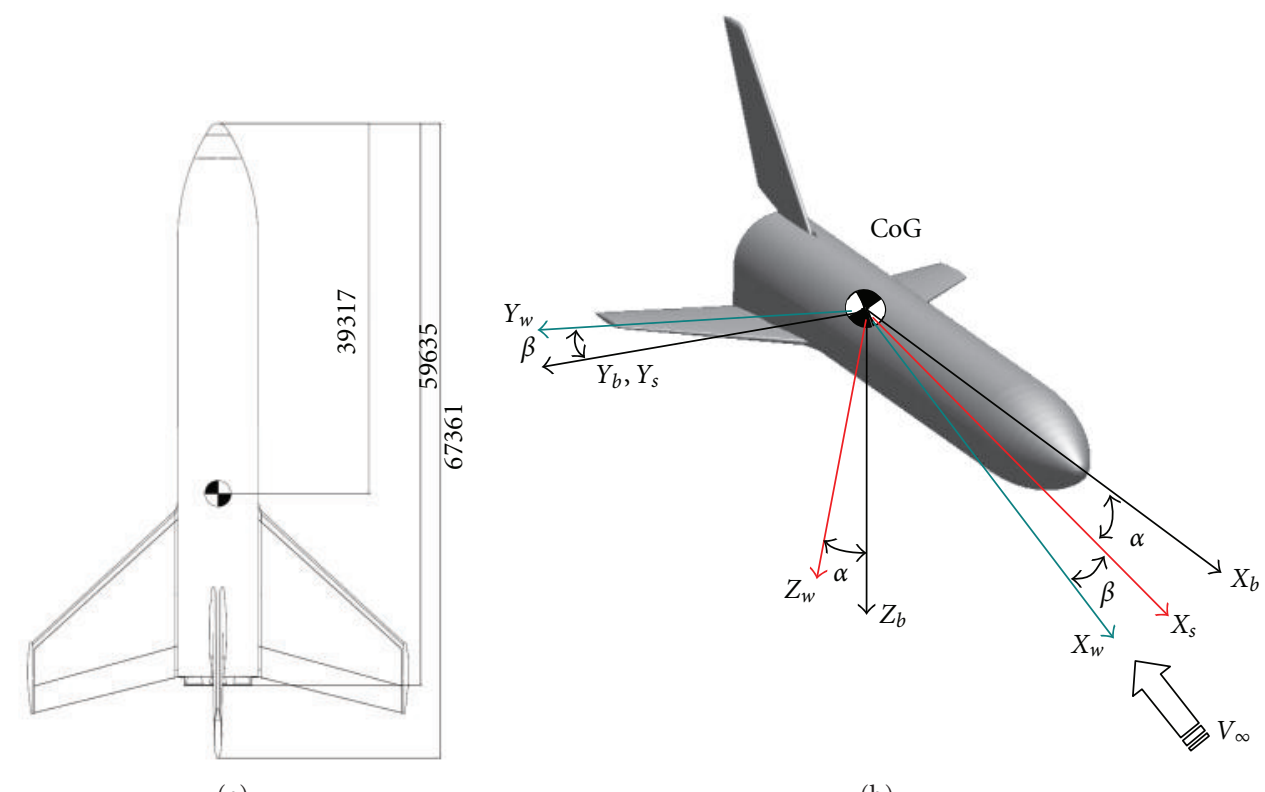

(a)

(b)

FIGURE 6: SOH-VTO Hopper aerodynamic reference parameters (a) and Reference frames (b).

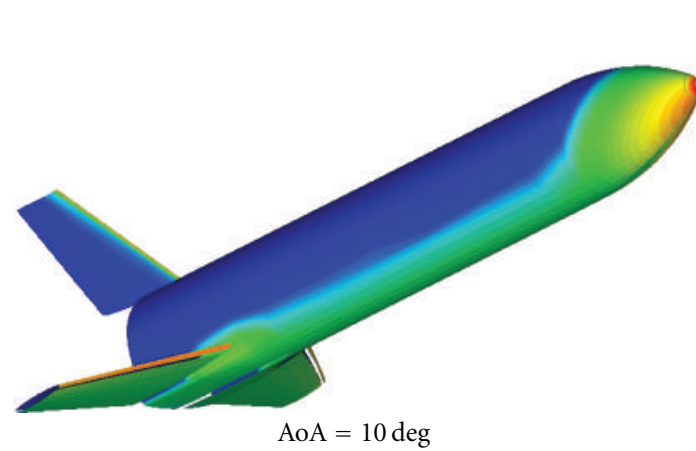

(a)

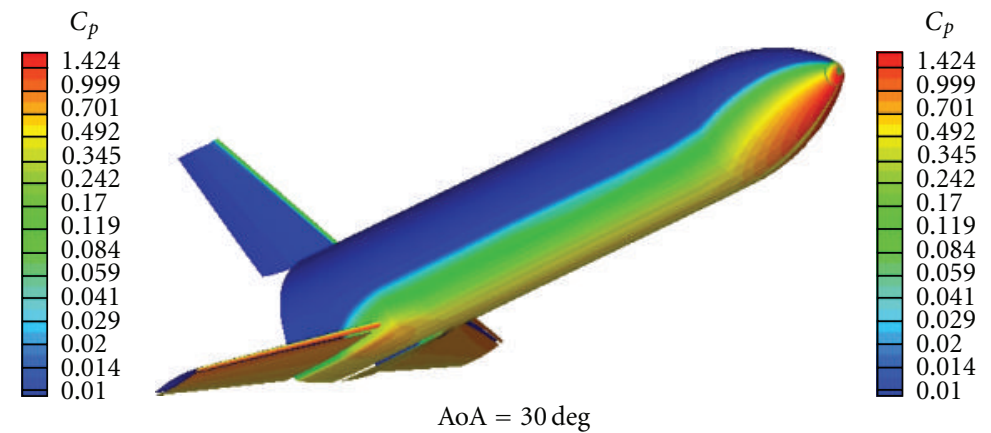

(b)

Figure 7: SOH-VTO Hopper. Pressure coefficient contours on the vehicle surface at $M_{\infty}=5$.

Neither lateral directional analysis nor wing and body flap effects have been taken into account in this paper.

5.3. Reference Coordinate System. In Figure 6(b), the used reference frames are shown; the subscript " $b$ " indicates the Body Reference Frame (BRF), while "w" indicates the Wind Reference Frame (WRF). The origin of both reference systems is in the centre of gravity ( $\mathrm{CoG}$ ) of the VTO-SOH configuration. The pole for the calculation of the moment coefficients is assumed at the vehicle nose. The following convention for the aerodynamic coefficients is adopted, that is, the convention usually adopted in flight mechanics: angle of attack $(\alpha)$ is positive when the free stream hits the vehicle form the bottom up; axial force coefficient $\left(C_{A}\right)$ is positive when force is pushing in front of the vehicle towards the base; normal force coefficient $\left(C_{N}\right)$ is positive when force is pushing on belly side of vehicle toward up; pitching moment coefficient $\left(C_{\mathrm{My}}\right)$ is positive when the aircraft puts the nose up.

\section{VTO Hopper: Synthesis of Results for Clean Configuration Aerodynamics}

For each Mach number, aerodynamic data refer to viscous analyses. As an example of the engineering aerodynamic database of the SOH-VTO Hopper concept in clean configuration, performed in this work, results for $M_{\infty}=5$ are summarized in Figure 7, where the pressure coefficient distribution over the wetted vehicle surface for two AoAs (i.e., 10 and $30 \mathrm{deg}$ ) is reported.

Ranging $\alpha$ from 10 to $30 \mathrm{deg}$, as highlighted by pressure coefficient contours, the Hopper configuration changes its 


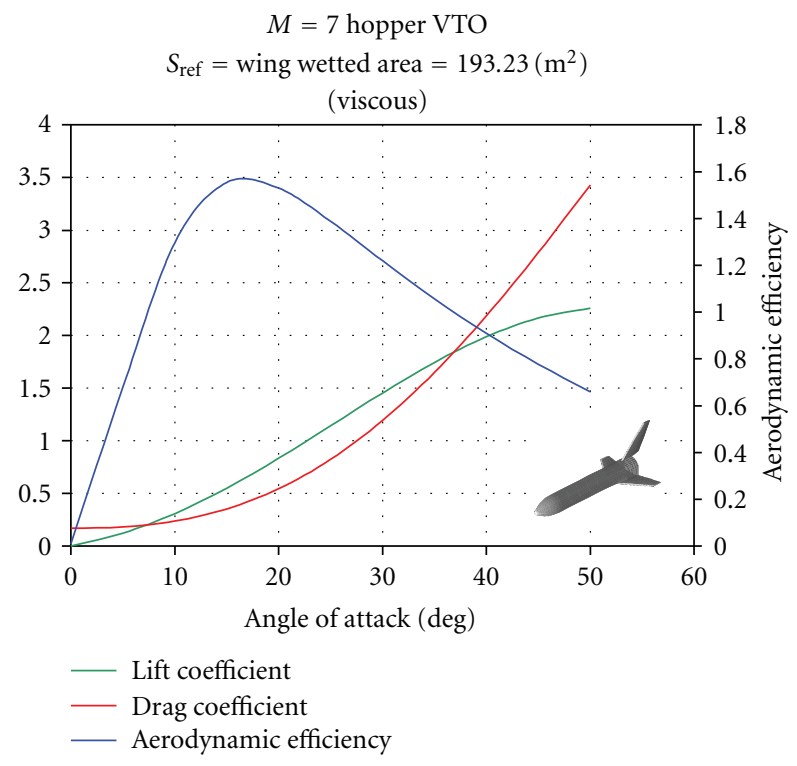

(a)

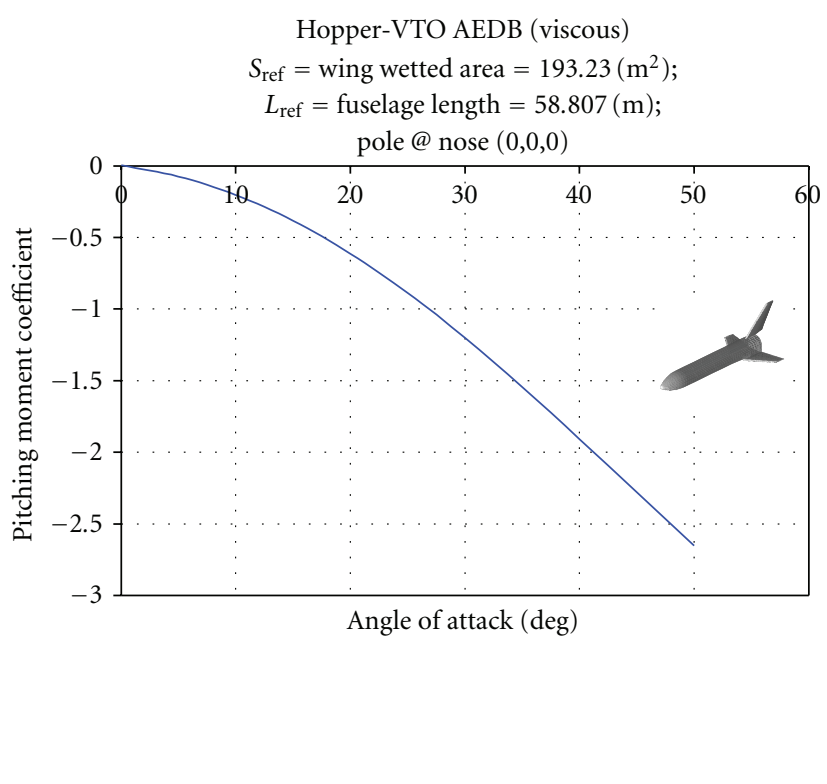

(b)

Figure 8: VTO Hopper. Aerodynamic characteristics and Pitching moment coefficient at $M_{\infty}=7$.

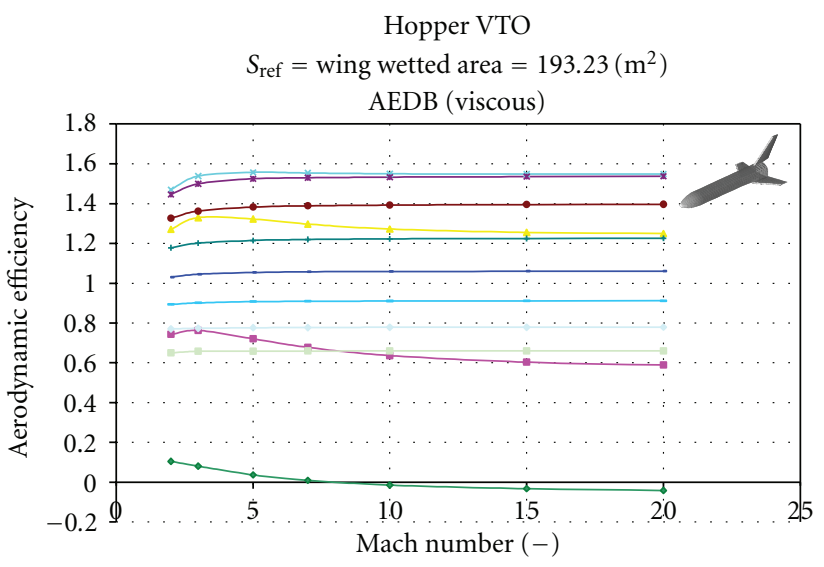

$$
\begin{aligned}
& \therefore \mathrm{AoA}=0^{\circ} \longrightarrow \mathrm{AoA}=30^{\circ} \\
& \because \mathrm{AoA}=5^{\circ} \quad-\mathrm{AoA}=35^{\circ} \\
& \because \mathrm{AoA}=10^{\circ} \longrightarrow \mathrm{AoA}=40^{\circ} \\
& \because \mathrm{AoA}=15^{\circ} \longrightarrow \mathrm{AoA}=45^{\circ} \\
& \because \mathrm{AoA}=20^{\circ} \longrightarrow \mathrm{AoA}=50^{\circ} \\
& \rightarrow \mathrm{AoA}=25^{\circ}
\end{aligned}
$$

Figure 9: SOH-VTO Hopper. Aerodynamic efficiency versus Mach number, for different AoA.

aerodynamic performance. For instance, Figure 8 shows that starting from $\alpha=0 \mathrm{deg}$, the VTO Hopper aerodynamic efficiency straightly increases reaching the peak of about 1.6 at $\alpha=15 \mathrm{deg}$, and then it decreases up to about 0.9 at $\alpha=40$ deg. A similar behavior (due to the effects of AoA) will be expected for the heat flux density distribution within the aerothermodynamic analysis, as recognized hereinafter.
In conclusion, looking at Figure 9 one can appreciate an overview of launcher's aerodynamic efficiency for the whole Mach number and AoA ranges. As clearly shown, the Oswatich (Mach independence) principle is satisfied starting already from Mach $=7$ (It is worth noting that no real gas effects have been taken into account).

Note that lift-to-drag ratio $(L / D)$ is the most important feature of the vehicle aerodynamic performance, which has a direct impact on the down-range capability of a reentry vehicle that reaches the nominal landing site (DRLS) at the end of an unpowered gliding flight [5].

\section{SOH-VTO Hopper Aerothermodynamic Analysis}

The aerothermodynamic analysis summarized in this paper refers to the design trajectory profile investigated for the VTO Hopper in the FLPP study. Stagnation points on the vehicle fuselage and on three different wing sections have been monitored as reference points. As done in the aerodynamic analysis, only engineering methods have been utilized to build the preliminary ATDB of the VTO vehicle concept.

7.1. Aerothermodynamic Features of the SOH-VTO Hopper Configuration. The vehicle forebody is characterized by a simple cone-sphere configuration, with a cylindrical fuselage shape. The geometry shows smooth streamlined surfaces in the upper and lower sides of fuselage to prevent local dangerous overheating, with a constant circular cross section up to the fuselage-wing interface. The fuselage nose radius $\left(R_{N}\right)$ is equal to $1 \mathrm{~m}$, while the wing is swept back by $45.17 \mathrm{deg}$ and is blended into the fuselage to minimize wingbody interference heating. 


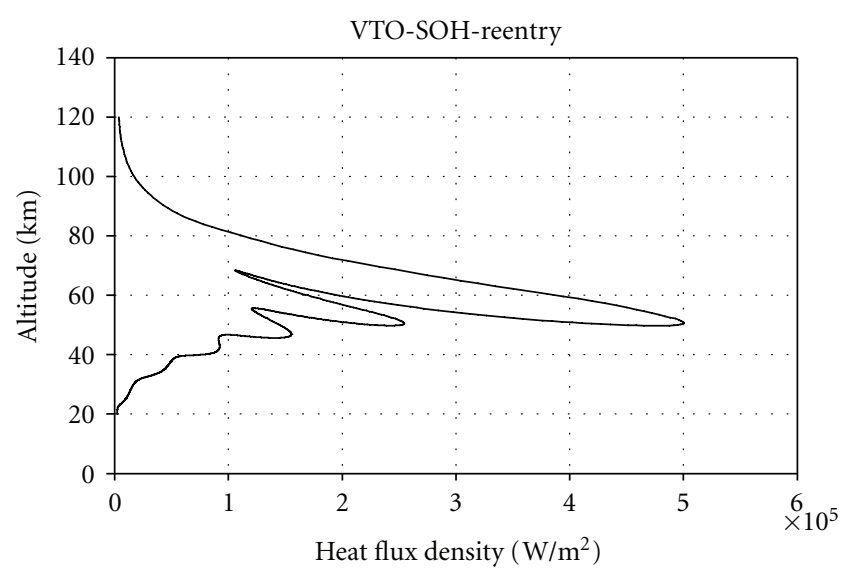

(a)

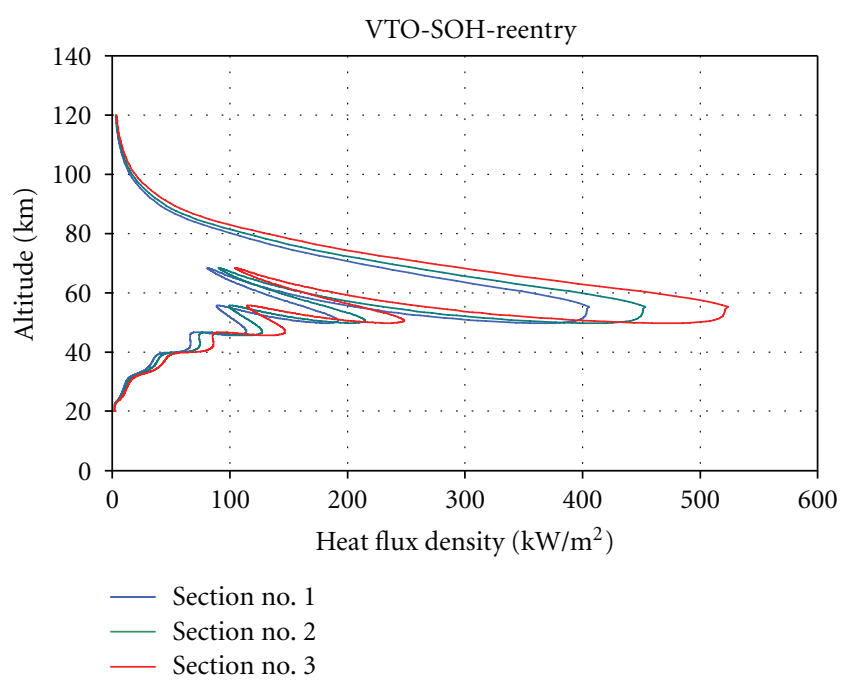

(b)

FIGURE 10: Altitude versus heat flux density profiles for fuselage nose (a) and wing sections nos. 1, 2, and 3.

7.2. SOH-VTO Hopper Aerothermal Environment. By flying, the work done by aerodynamic drag in braking the vehicle heats the surface with a severity that depends on the reentry vehicle configuration. Therefore, based on the reentry flight profile (see Figure 3), it follows the aeroheating environment that the VTO Hopper has to withstand along the atmospheric descent. This aeroheating environment is dimensioning for the TPS which protects the vehicle from the high-thermal loads during reentry.

In order to characterize the VTO Hopper aerothermal environment, several control points of the vehicle configuration have been considered. They are the stagnation point of the fuselage nose as well as of three wing sections (see Figure 15).

To build the heat transfer density profile for the fuselage stagnation point the Detra, Kemp and Riddell [6] relationship has been employed:

$$
\dot{q}=\frac{18300}{\sqrt{R_{N}}} \rho_{\infty}^{0.5}\left(\frac{v_{\infty}}{10^{4}}\right)^{3.05}\left[\frac{W}{\mathrm{~cm}^{2}}\right]
$$

while the Gomg's relationship is applied for the wing leading edge $[6,7]$

$$
\dot{q}_{\text {wing }}=\frac{1}{\sqrt{2}} \frac{1}{\sqrt{R_{\text {cyl }}}} \dot{q}_{R_{N}=1} \cos ^{1.2} \Lambda_{\mathrm{eff}}
$$

where $\Lambda_{\text {eff }}$ is the effective swept angle:

$$
\begin{gathered}
\sin \Lambda_{\text {eff }}=\sin \Lambda \cos \alpha, \\
\cos \Lambda_{\text {eff }}=\sqrt{1-\sin ^{2} \Lambda_{\text {eff. }}}
\end{gathered}
$$

It is worth underlining that this analysis is reasonable and applicable only in the continuum flow regime.
The heat flux density profiles estimated with (3) and (4) as a function of altitude, and with respect to the fuselage nose and wing leading edge (for three wing sections), are reported in Figure 10.

In Figure 11 (the right side is an enlargement of the critical heating zone of reentry profiles), the time histories of the aerothermal environment at the launcher's nose are shown. Note that the thermal load distribution is reported together with the AoA profile the reentry vehicle exhibits during descent. The time history of heat flux profiles for each wing control section is shown in Figure 12.

As one can see, the reentry trajectory results in a peak heating at fuselage nose of about $500 \mathrm{~kW} / \mathrm{m}^{2}$, that is reached when the VTO launcher is flying at $M_{\infty}=13.4$ and $\mathrm{AoA} \approx 30 \mathrm{deg}$, at an altitude of $50.8 \mathrm{~km}$.

On the other hand, looking at what happens to the wings, both the right sides of Figure 10 and Figure 12 highlight that the spanwise distribution of heat flux at WLE is expected to increase ranging from wing root to tip due to the smaller WLE radius (relative leading edge radius of $4.5 \%$ ) and that the wing shape (e.g., wing swept angle and wing leading edge radius profile in spanwise) is characterized by an aeroheating at leading edge that reaches values close to that of the fuselage nose.

The heating profiles, reported above, lead to an integrated heat load $Q$ that is expressed by

$$
Q_{\mathrm{sp}}(t)=\int_{t_{E}}^{t} \dot{q}_{\mathrm{sp}}(\tau) d \tau,
$$

where $t_{E}$ is the time at the entry point, when the vehicle initiated the reentry.

The time histories of the heat load per unit area $\left(\mathrm{MJ} / \mathrm{m}^{2}\right)$ for nose and wing sections, according to (6), are reported in Figure 13. Both heat flux and integrated heat load are fundamental for the TPS design analyses [8]. The heat flux distribution on the aeroshape dictates the choice of thermal 


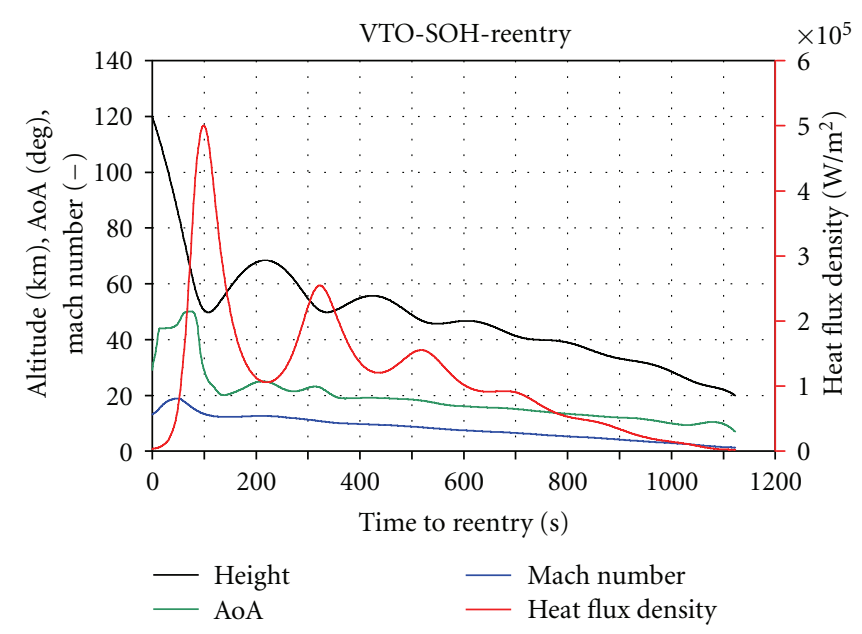

(a)

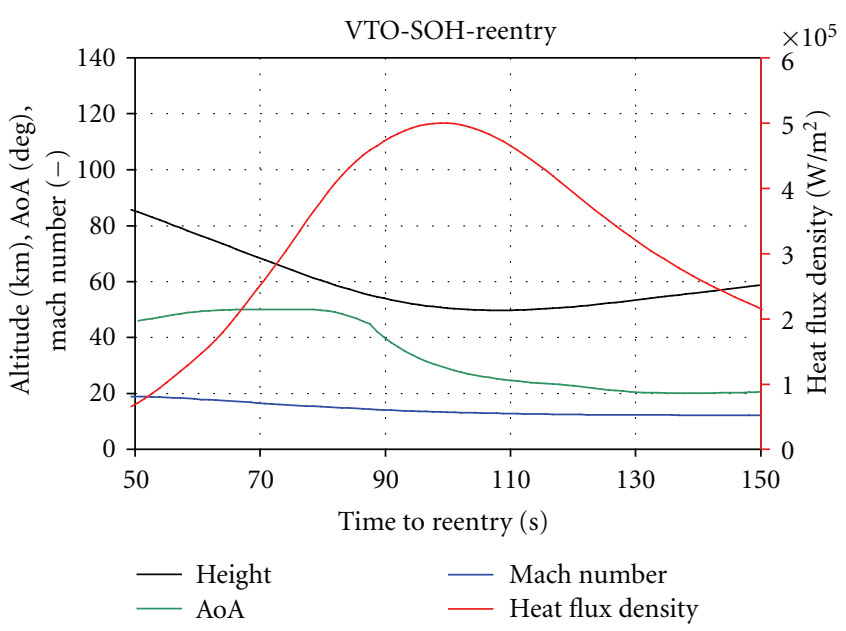

(b)

FIGURE 11: Aeroheating environment versus entry interface time.

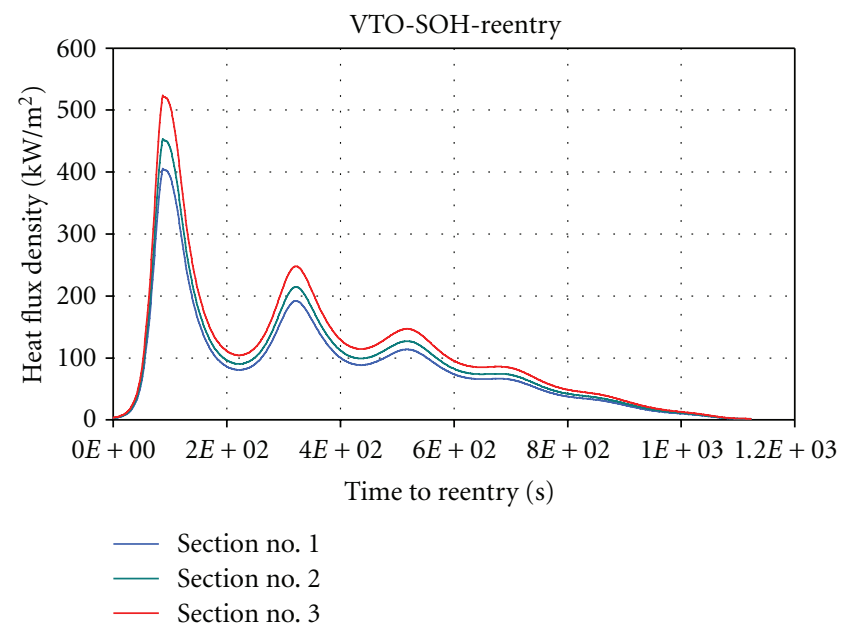

Figure 12: Heat flux density profiles versus entry interface time, at WLE of sections nos. 1, 2, and 3.

protection material (TPM) able to withstand this thermal loading as well as the TPS configuration; the integrated heat load suggests the sizing of the thermal shield thickness [8].

The calculations of heat loads led to the following conclusions: due to the steep reentry, the VTO Hopper experiences a short heat pulse on its windward side, which drives maximum heat flux and surface temperature to levels comparable to RLVs coming down from LEO orbit; maximum heat fluxes averaged over the surface of the vehicle are moderate if compared with RLV returning from orbit; the short heat pulse on the windward side is manageable with ceramic hardcover TPS but restricts the application of specifically lighter metallic TPS; catalytic surface effects on the large vehicle are not significant.

7.3. General Inputs for Aerothermodynamic Data Set Generation. In order to provide the heat flux distribution over vehicle surface (only fuselage and wing), a number of trajectory flight conditions (trajectory check points) have been considered, in the light of the trajectory-based design approach [2,3]. Figure 14 gives an overview of the trajectory zone, where check points have been established while their free-stream conditions are reported in Table 1.

The points are selected on the trajectory in such a way to duplicate the area under the heat pulse, which markedly drives the vehicle thermal shield design. Finally, numerical computations, based on laminar flow conditions with the air modelled as a perfect gas, refer to cold wall boundary conditions.

7.4. VTO Hopper: Synthesis of Results for Clean Configuration Aerothermodynamics. The engineering aerothermodynamic database of the VTO Hopper concept in clean configuration provides vehicle thermal loading by means of heat flux density profiles on different vehicle sections, as for example, the fuselage centerline, at cold wall $\left(T_{w}=300 \mathrm{~K}\right)$ conditions. In order to facilitate the comparison among the results and the application for TPS sizing, the heat fluxes have been provided along selected section lines of fuselage and wing, as shown in Figure 15. Five slices have been selected on fuselage and three slices on the wing surface.

The following plots show the results obtained at trajectory check points compared on fuselage sections 1 and 5 (i.e., the leeward and windward centerline), and on wing section no. 1 in order to characterize the fuselage and wing thermal loading. It must be underlined, however, that these aeroheating results have not been obtained by means of accurate and more reliable CFD computations. Therefore, a proper margin should be adopted in recognizing vehicle aerothermodynamic data. This is especially true considering aeroheating estimates on wing, as it will be clarified hereinafter. For more details see [9] where the effects of both turbulent flow conditions and flow dissociation on VTO preliminary design are also shown. 


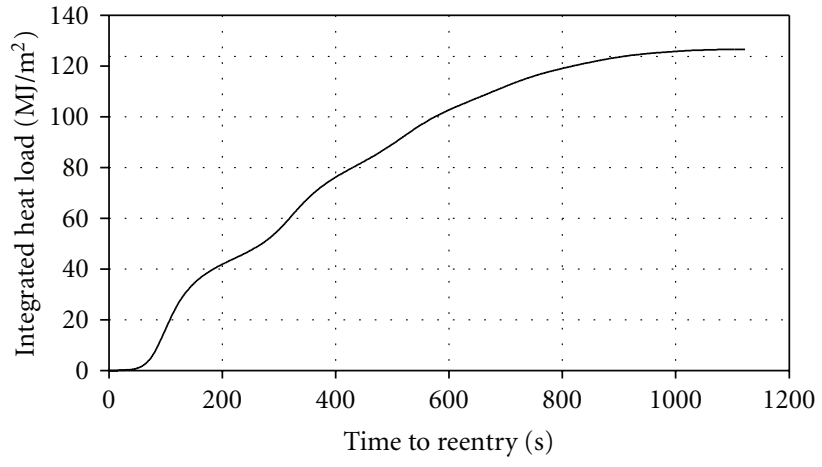

(a)

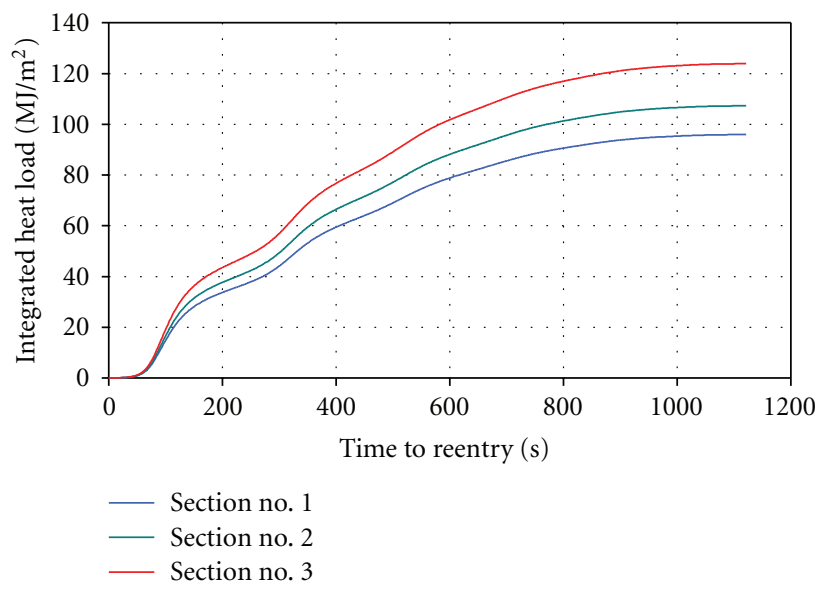

(b)

FIGURE 13: SOH-VTO Hopper heat load profiles for nose (a) and for wing sections (b).

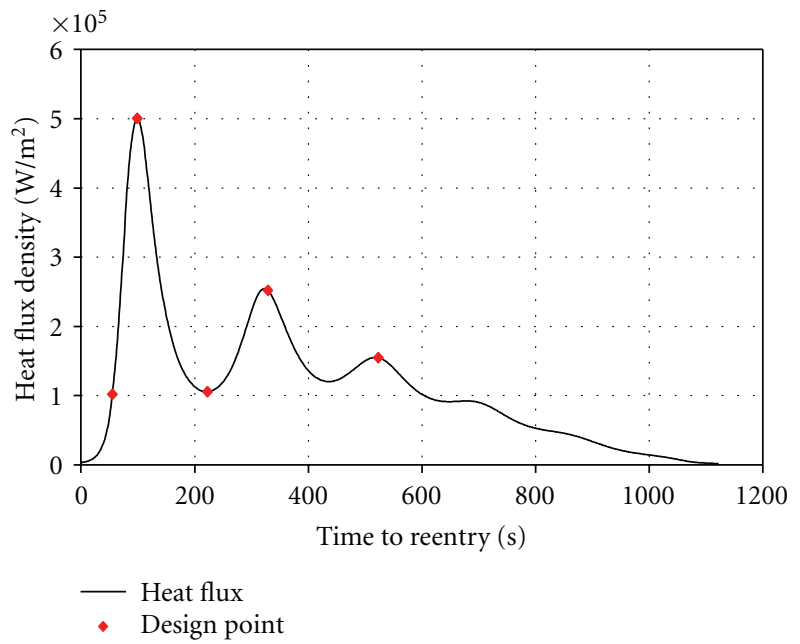

(a)

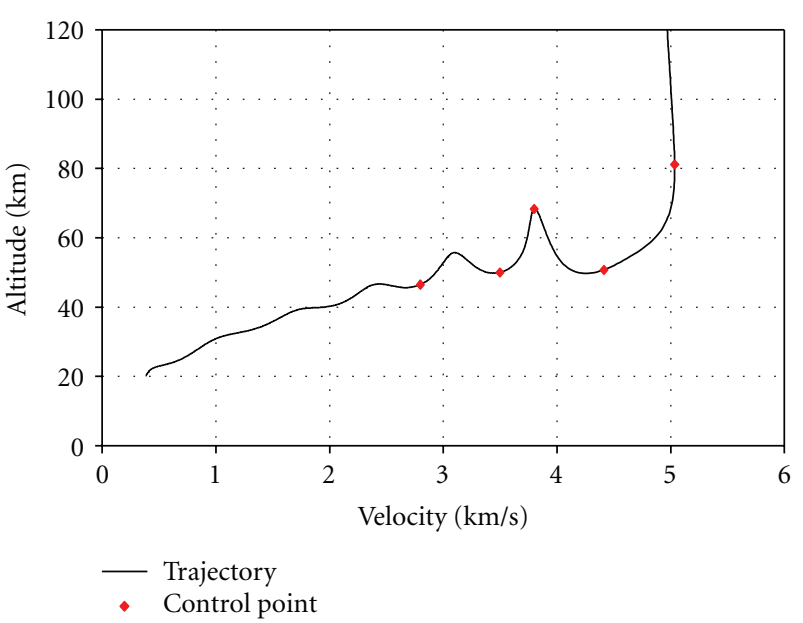

(b)

FIgURe 14: Time history of heat flux control points (a). Heat flux control points in the $H-v$ map (b).

7.5. SOH-VTO Hopper Fuselage Thermal Loading. Figure 16 shows the heat flux along the Hopper centerline (sections nos. 1 and 5) as evaluated at control points nos. 2 and 5 (see Table 1).

By analyzing this figure, very interesting features can be taken into account for a reliable TPS design for the $\mathrm{SOH}-\mathrm{VTO}$ Hopper fuselage. For example, when the results obtained at different AoA are compared it results that at $\alpha=18$ deg the vehicle leeside reaches higher heat flux, while at $\alpha=30 \mathrm{deg}$ the windside is the most solicited vehicle part, as expected.

7.6. SOH-VTO Hopper Wing Thermal Loading. In this paragraph, the results of aerothermodynamic analysis collected on Hopper wing section no. 1 (see Figure 15) are reported. In Figure 17, the heat flux along Hopper airfoil (section no. 1) as evaluated at control points nos. 2 and 4 (see Table 1) is shown. By analyzing these figures, very interesting features can be taken into account for a reliable TPS design for the SOH-VTO Hopper wing.

\section{Reliability of Design Activities}

In the following two paragraphs, several comparisons between results of present analyses and data provided by more reliable CFD computations are made in order to assess the error margins of engineering-based design analyses. In fact, since these aerodynamic and aerothermodynamic analyses are based on empirical correlations and approximate theories, it is important that they are calibrated against more accurate CFD results.

8.1. SOH-VTO Hopper Aerodynamics. On the basis of the VTO reentry scenario of Hopper (see Figure 18), a number of flight conditions have been chosen to carry out CFD computations. Those numerical computations allow to anchor the 


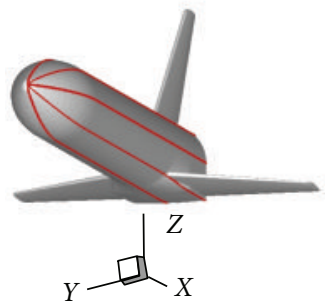

Section no. 1

\begin{tabular}{|c|c|}
\hline $\begin{array}{c}\text { Section } \\
\text { /no. }\end{array}$ & $\begin{array}{c}\phi \\
(\mathrm{deg})\end{array}$ \\
\hline 1 & 0 \\
\hline 2 & 45 \\
\hline 3 & 90 \\
\hline 4 & 135 \\
\hline 5 & 180 \\
\hline
\end{tabular}
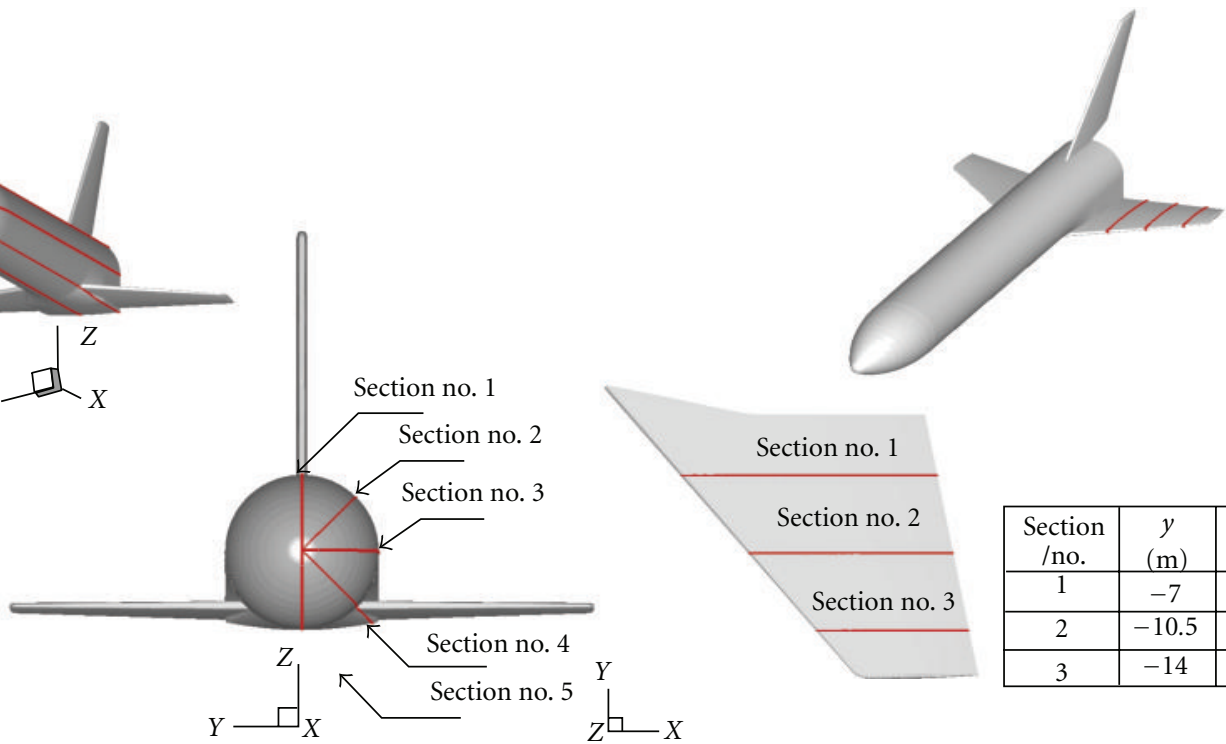

Figure 15: VTO Hopper fuselage and wing sections where heat fluxes are provided.

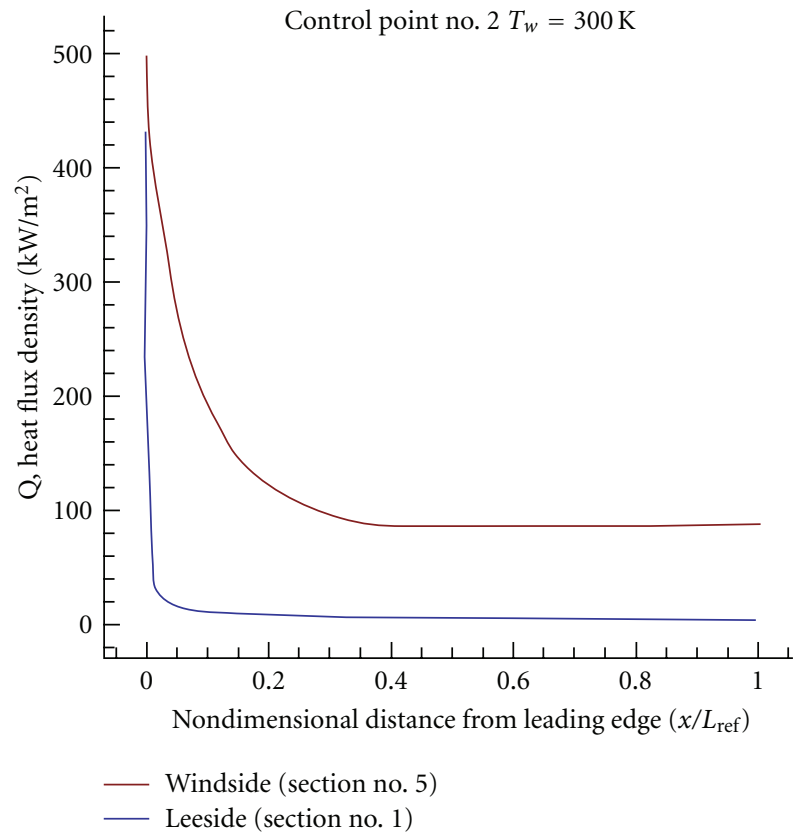

(a)

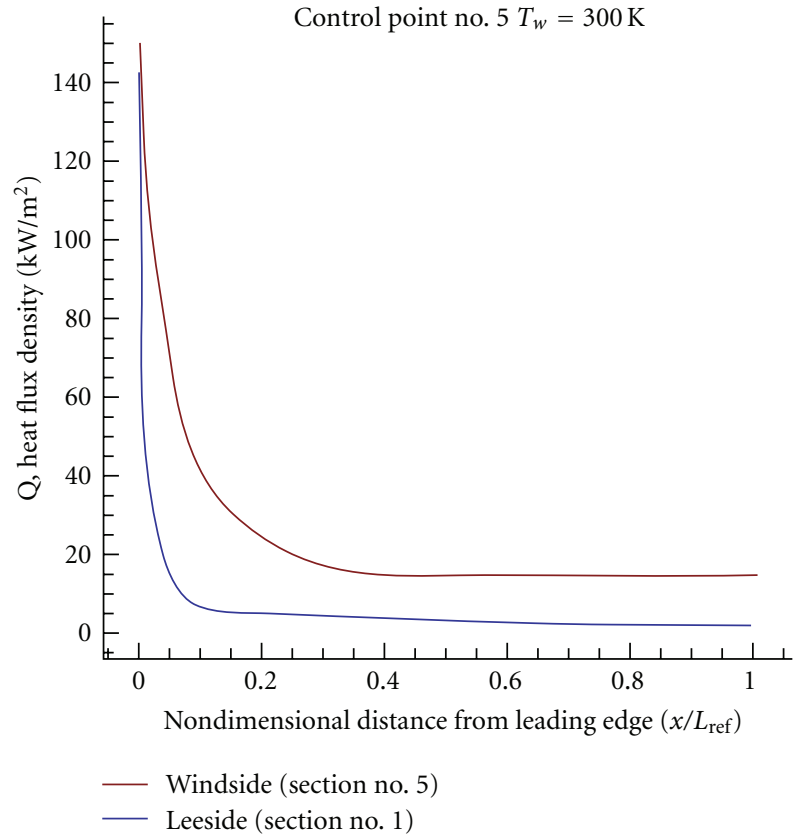

(b)

Figure 16: Heat Flux along Hopper centerline (sections nos. 1 and 5) at control points nos. 2 (a) and 5 (b). Comparison between vehicle windside and leeside.

engineering analyses in order to verify the accuracy attained with the simplified analyses and to focus on some critical design aspects not predictable with engineering tools. The selected control points are reported in Figure 18, while the CFD test matrix is summarized in Figure 19.

As one can see, each check point lies within the flight scenario foreseen for a typical mission profile of the VTO launcher concept.
Each red box in Figure 19 identifies a CFD run (e.g., check point); therefore, the results of twelve CFD Euler computations are reported in the following. All CFD results refer to grid converged computations.

Figure 20 shows the Mach number contour field when the VTO Hopper vehicle is flying at $M_{\infty}=5$ and $\alpha=10 \mathrm{deg}$. Looking at the contour field in the vehicle symmetry plane one can appreciate the strong bow shock that occurs ahead 


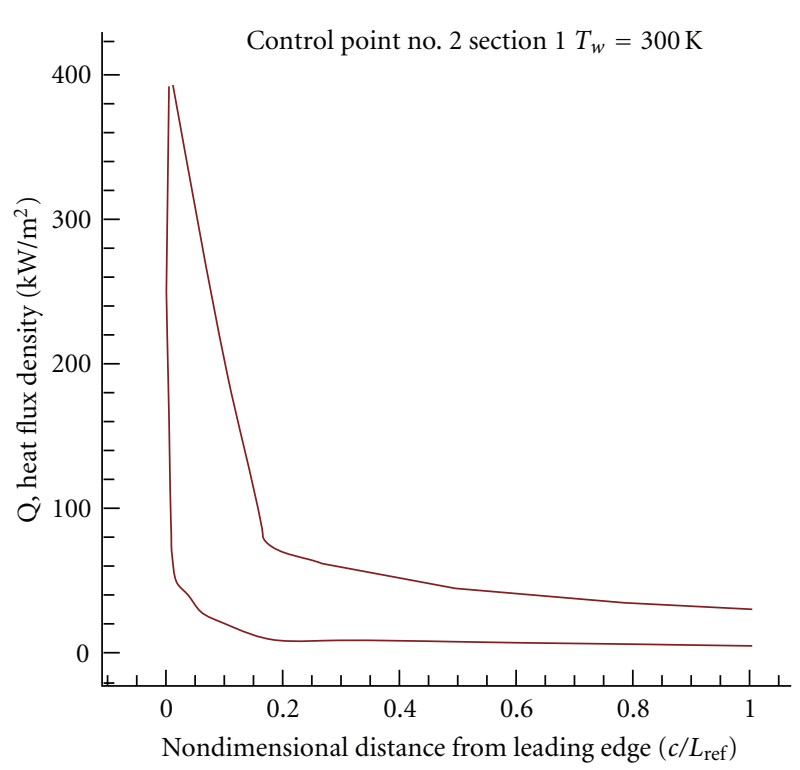

(a)

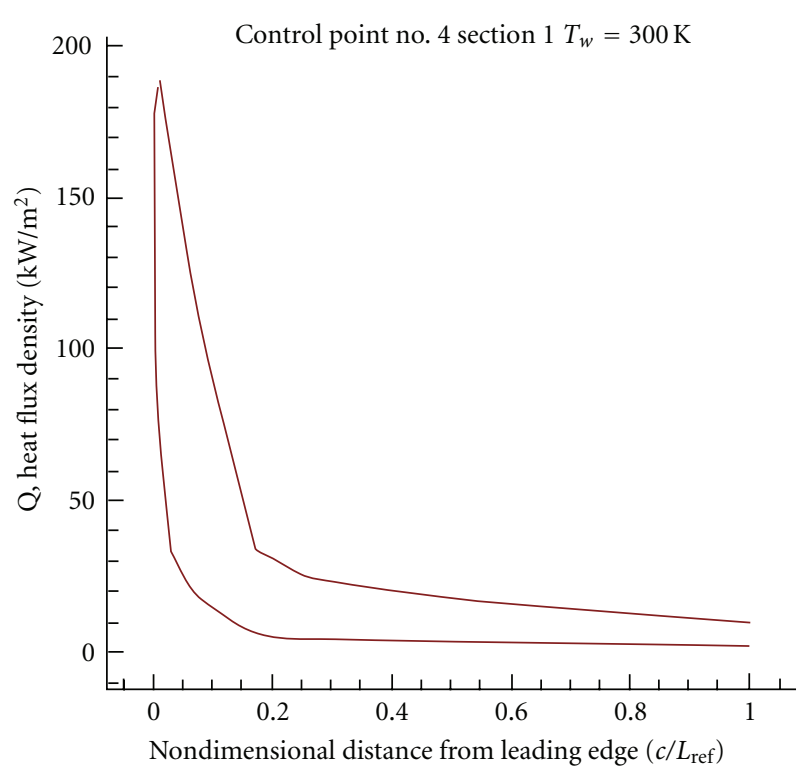

(b)

Figure 17: Heat Flux along Hopper airfoil (section no. 1) at control points nos. 2 (a) and 4 (b).

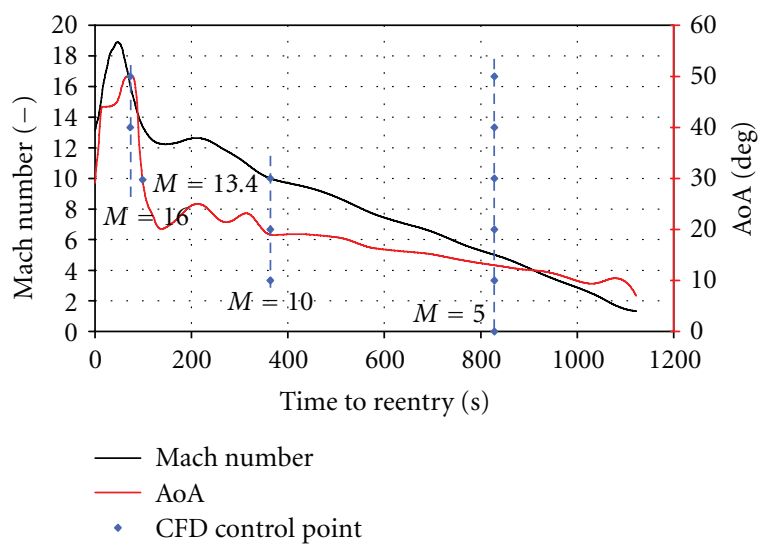

FIGURE 18: SOH-VTO Hopper reentry scenario with control points for CFD analyses.

\begin{tabular}{|c|c|c|c|c|}
\hline \multirow[t]{2}{*}{$\begin{array}{l}\text { AoA } \\
\text { (deg) }\end{array}$} & \multicolumn{4}{|c|}{$\begin{array}{c}\text { Mach } \\
(-)\end{array}$} \\
\hline & 5 & 10 & 13.4 & 16 \\
\hline 0 & & & & \\
\hline 10 & & & & \\
\hline 20 & & & & \\
\hline 30 & & & & \\
\hline 40 & & & & \\
\hline 50 & & & & \\
\hline
\end{tabular}

Figure 19: CFD Test Matrix.

of vehicle during descent. Further information concerning the bow shock shape can be recognized in Figure 21, where Mach number contours on different cross planes are shown when the booster is flying at $M=10$ and $\alpha=20 \mathrm{deg}$.
This shock surface envelopes the vehicle and may impinge on wing leading edge thus increasing locally the heat flux (overheating) that the vehicle thermal shield has to withstand (see Figure 22).

Therefore, analyses of shock-shock interaction (SSI) with overloads (pressure and heat flux) at impingement are mandatory for a reliable vehicle TPS design. Further flow field features can be recognized in Figure 20 where the normalized pressure contour field is also shown.

Concerning the reliability of predicted aerodynamic coefficients from Figures 23, 24, and 25, a good agreement between the estimated aerodynamics and the CFD data can clearly be noted.

As clearly evident, results of engineering-based approach and CFD computations compare very well at each Mach number and AoA considered. The maximum difference has been found at Mach 16 and $\alpha=50 \mathrm{deg}$ which is comprised within an error bar of $10 \%$.

8.2. SOH-VTO Hopper Aerothermodynamics. As far as the wing is concerned, it is worth to underline that engineering analyses refer only to wing-alone condition, considering that the effects of vehicle bow shock (e.g., the detached shock ahead of vehicle) can be investigated only by means of more accurate CFD analyses. Therefore, differences on heat flux distribution between 1D BLM and CFD analyses are expected moving in spanwise direction toward the tip. In fact, the part of the wing that is behind the vehicle bow shock experiences different flow field conditions with respect to the free stream ones. This means that considering the presence of the bow shock (i.e., also a more realistic situation with respect to the free stream conditions), the heat flux is expected higher than the one evaluated by means of 1D BLM. Moreover, heat flux distribution in sections nos. 2 and 3 could be influenced by 


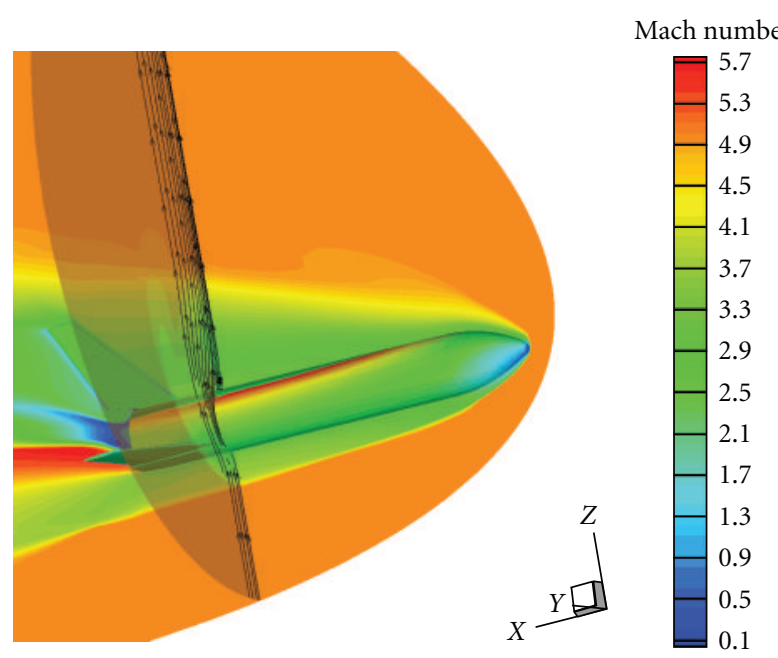

(a)

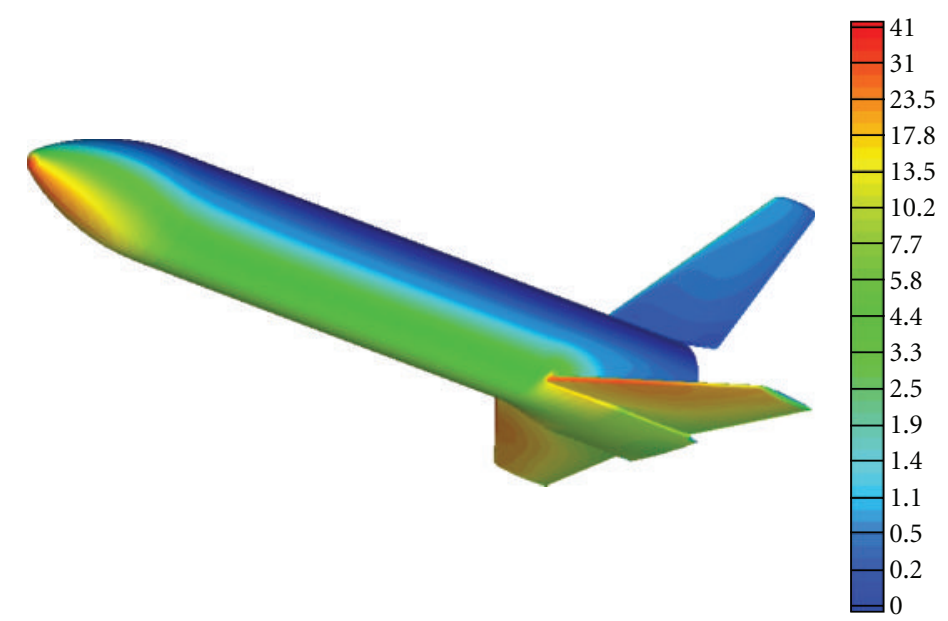

(b)

Figure 20: Mach no. contours (a). Normalized pressure contours on vehicle surface (b). Euler computation at $M_{\infty}=5, \alpha=10$ deg (a) and $\alpha=20 \operatorname{deg}(\mathrm{b})$.

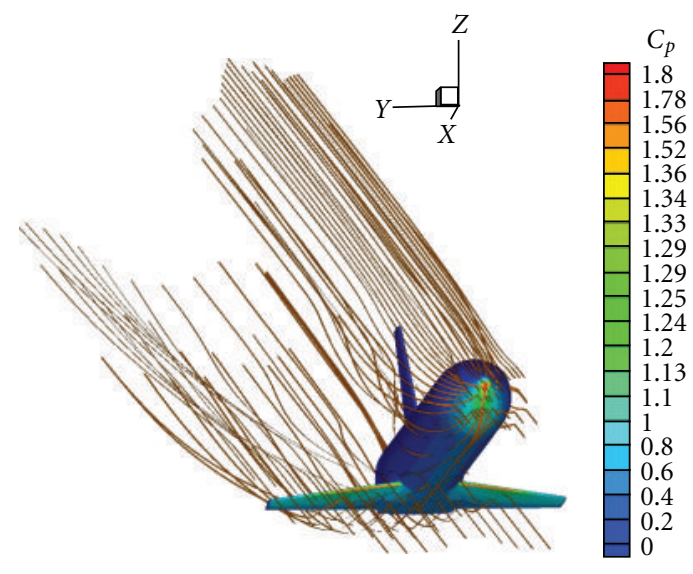

(a)

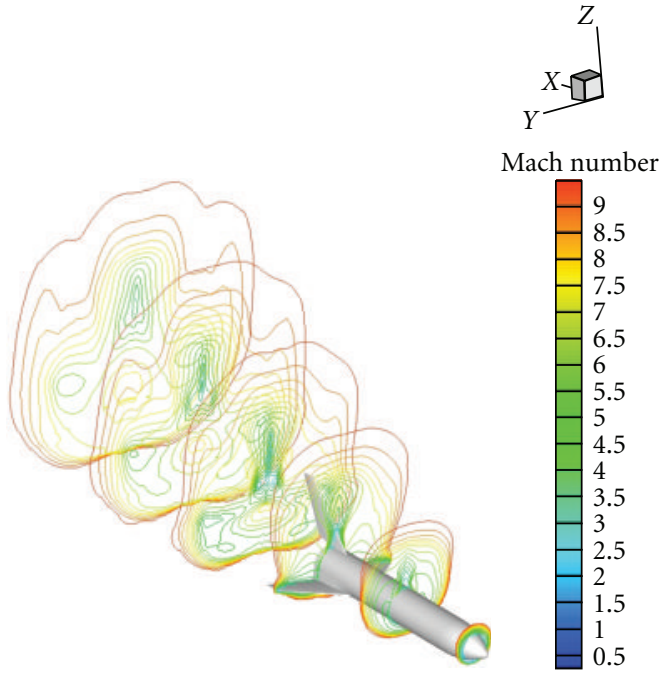

(b)

Figure 21: Pressure coefficient contours on vehicle surface with 3D streamtraces (left side). Mach no. contours on different cross planes. Euler computation at $M=10, \alpha=20 \mathrm{deg}$.

a vortex arising from the wing tip (that can be investigated only via CFD computations), and especially by the pressure spike on the wing leading edge due to the bow shock. Note that this pressure spike, followed by shock-shock interaction occurring between wing shock and bow shock, localizes a high heat load region on WLE and its position changes along the atmospheric descent, depending on Altitude, Mach, and AoA reentry profiles. This means that a proper margin of $30 \%$ should be adopted with respect to the engineering data.

In conclusion, it is worth underlining that as in the case of AEDB evaluation, rarefaction effects have to be taken into account in determining the heat flux distribution on the wing leading edge. Therefore, CFD and DSMC analyses are mandatory for a reliable TPS vehicle design, as vehicle design proceeds.

\section{Concluding Remarks}

Preliminary hypersonic aerodynamics and aerothermodynamics dataset for the reusable VTO Hopper concept, under investigation in the frame of the Future Launchers Preparatory Program of European Space Agency, have been carried out in the present work. The Hopper aerodynamics analyses refer to Mach number ranging from 2 to 20 and AoA from 0 to $50 \mathrm{deg}$, which are conditions covering the whole reentry scenario of the vehicle concept (space-based design approach). For the aerothermodynamic point of view, 


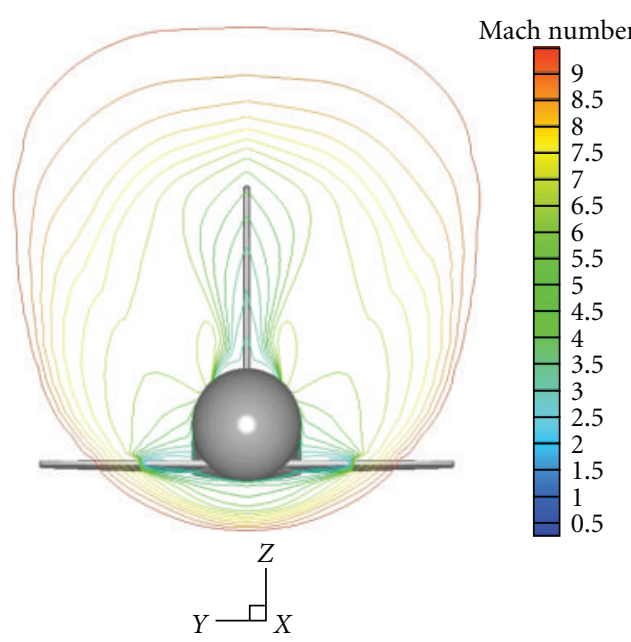

(a)

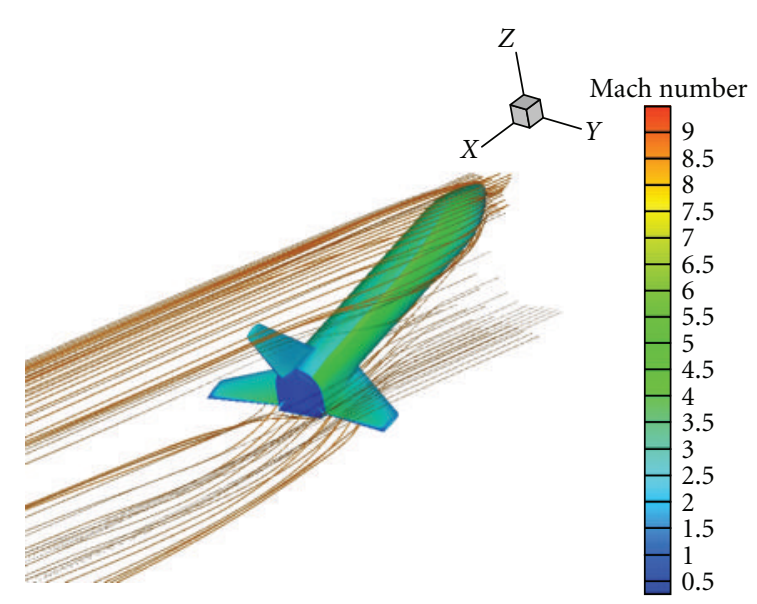

(b)

Figure 22: Mach no. contours in the cross plane where bow shock impinges over the wing (a). Mach no. contours on vehicle surface with $3 \mathrm{D}$ streamtraces. Euler computation at $M=10, \alpha=20 \mathrm{deg}$.

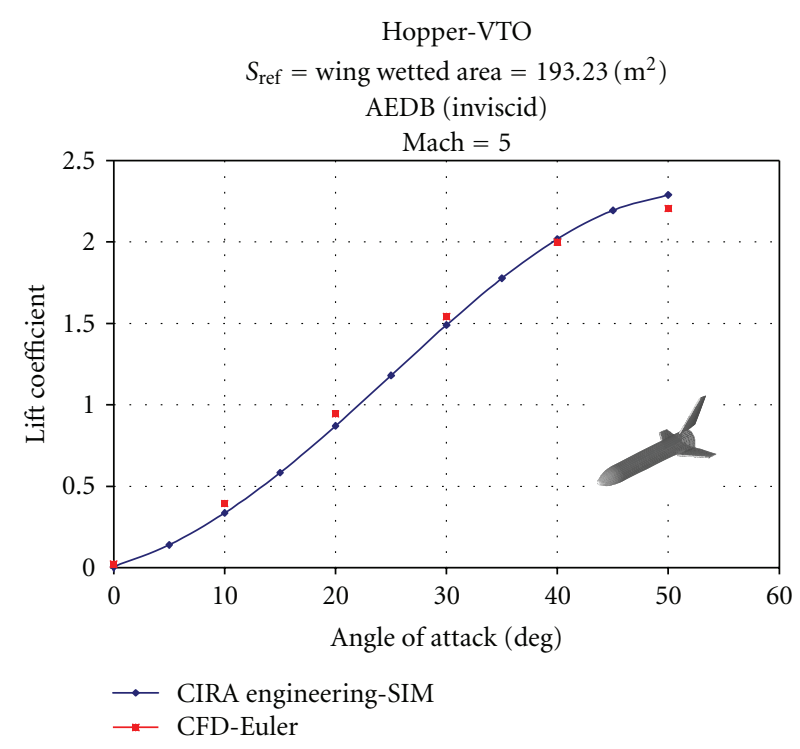

(a)

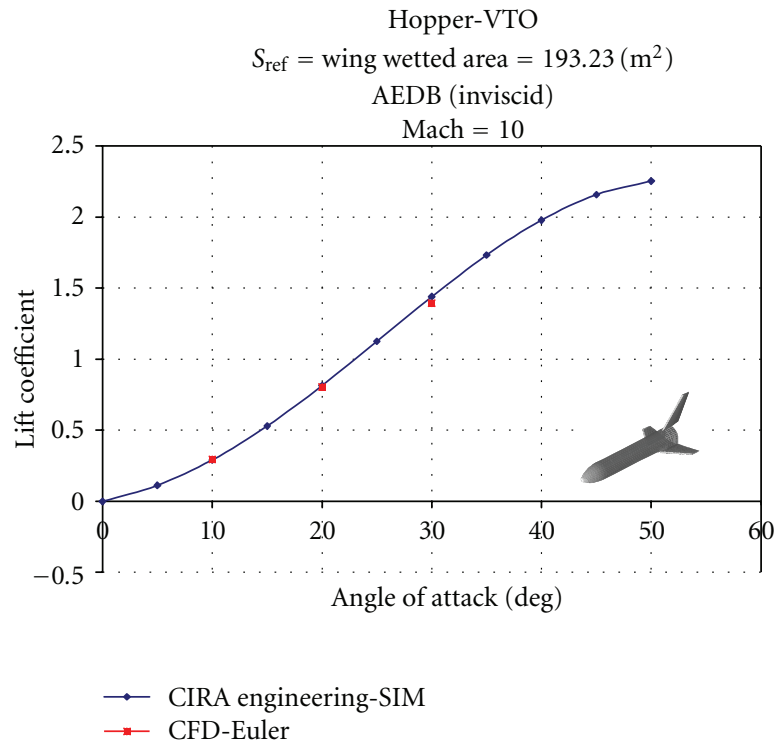

(b)

FIgURE 23: Lift coefficient versus AoA. Comparison between SIM and CFD Euler at $M_{\infty}=5$ and $M_{\infty}=10$.

selected points of the reentry trajectory have been simulated (trajectory-based design approach). It is worth underlining, however, that some results of the present analysis have not been carried out by means of accurate and more reliable CFD computations. Therefore, proper margins should be adopted in recognizing the whole vehicle aerodynamic and aerothermodynamic data.

In any case, the obtained results confirm that the difference between eulerian CFD and engineering-based design is smaller than $10 \%$ for aerodynamic coefficients, while a margin of about $30 \%$ has to be taken into account for what concerns the aerothermodynamic results. This fact confirms that surface impact methods and one-dimensional boundary layer method represent a reasonable preliminary design approach in order to accomplish the aerodynamic and aerothermodynamic characterization of a reentry vehicle across the hypersonic regime.

From this work very interesting features can be derived for a reliable aerothermal environment definition of the FLPP concept. For example, both the vehicle nose and wing leading edges experience a heat flux within $500 \mathrm{~kW} / \mathrm{m}^{2}$.

Note, in conclusion, that further analyses seem necessary on specific topics in order to increase the reliability of the aerodynamic and aerothermodynamic databases and to reduce the design margins. In particular, the attention has to be focused on real gas and rarefaction effects, as well 


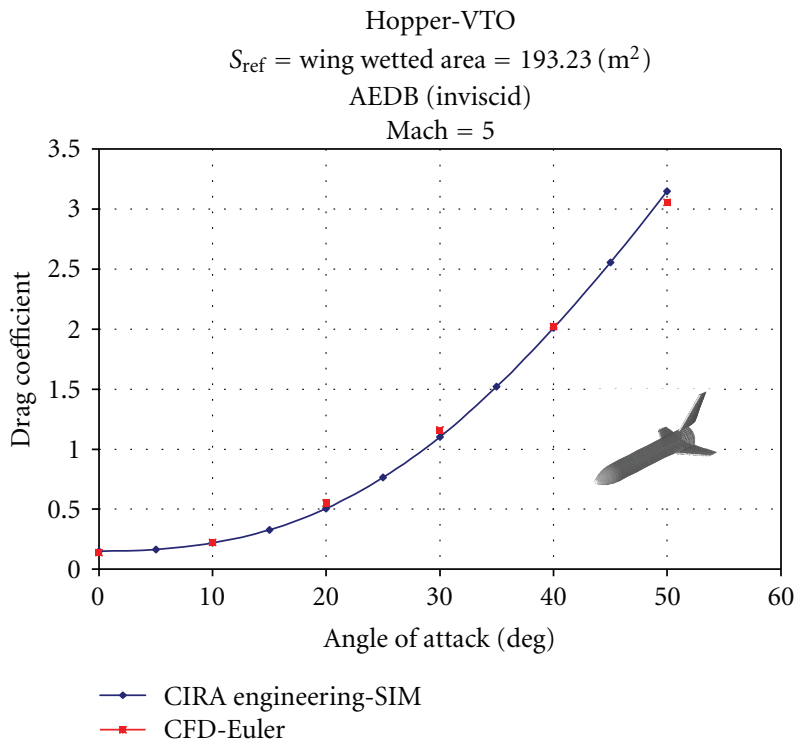

(a)

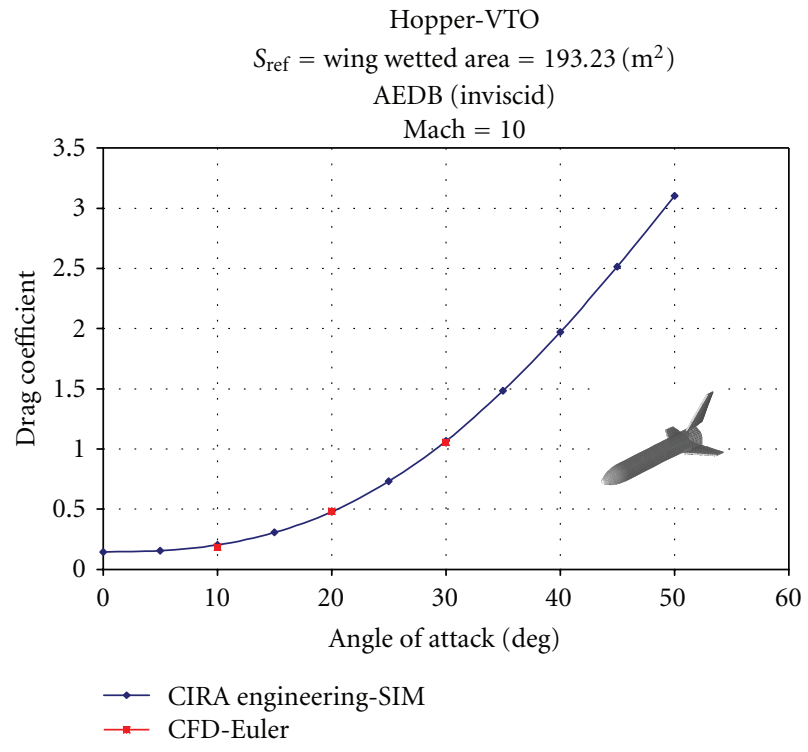

(b)

FIgure 24: Drag coefficient versus AoA. Comparison between SIM and CFD Euler at $M_{\infty}=5$ and $M_{\infty}=10$.

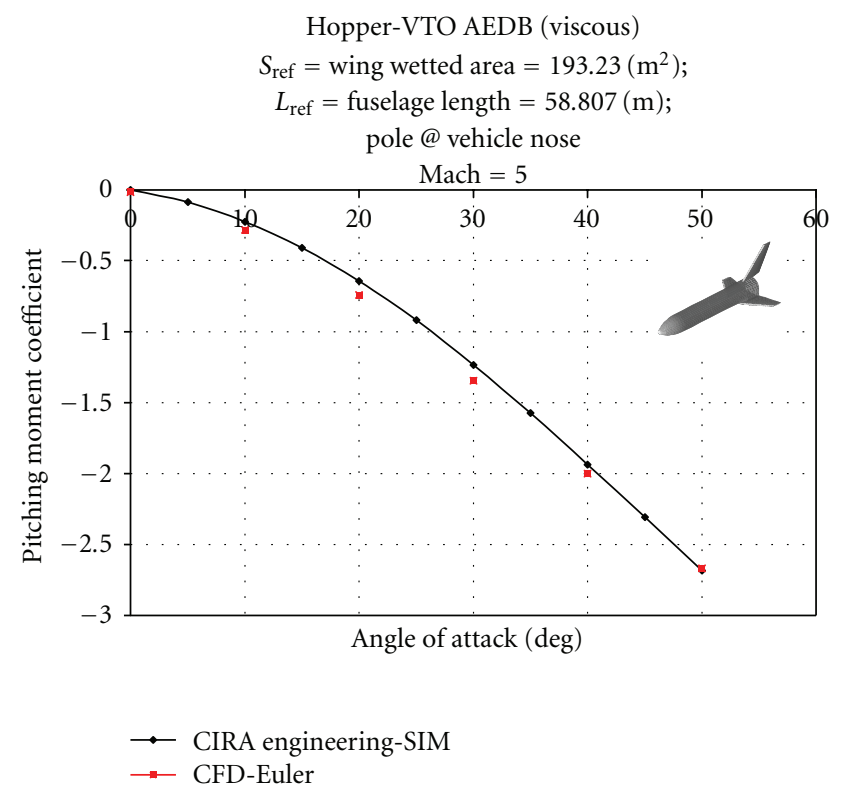

(a)

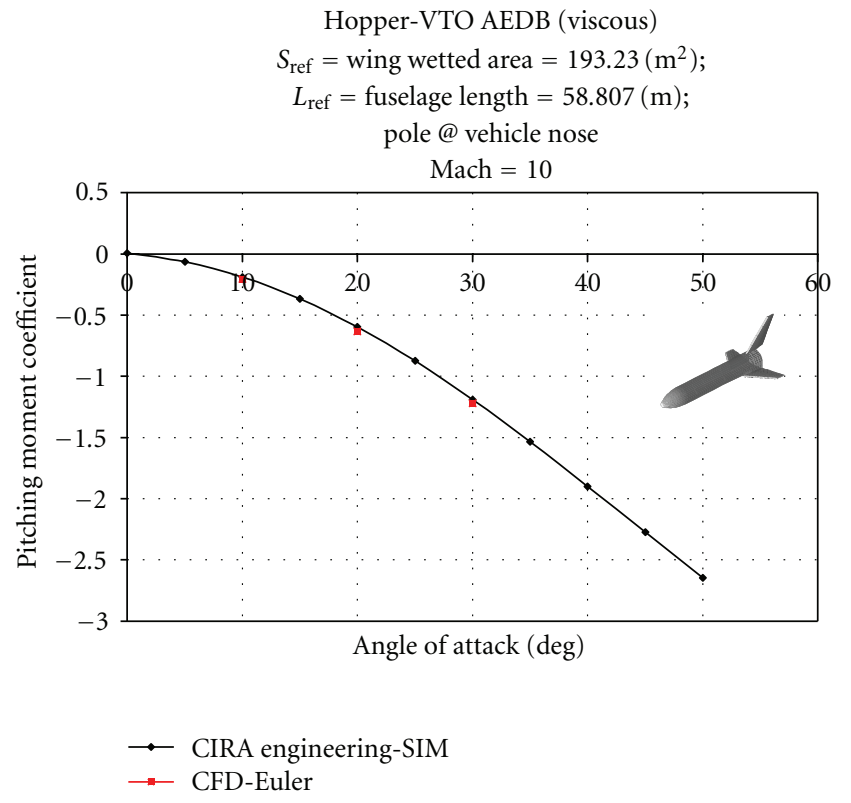

(b)

FIgure 25: Pitching moment coefficient versus AoA. Comparison between SIM and CFD Euler at $M_{\infty}=5$ and $M_{\infty}=10$.

as on shock-shock interactions and laminar-to-turbulent transition. The real gas effects can be important because, during atmospheric reentry, dissociation and ionization processes take place in the shock layer, which can have an influence on the aerodynamic coefficients. Real gas effects are expected to affect stability and control derivatives of vehicle, in particular its pitching moment, as highlighted by first U.S. Space Shuttle reentry (STS-1) where an unexpected higher nose-up pitching moment required a body-flap deflection twice the one predicted by the preflight analyses to trim the
Orbiter. Moreover, real gas effects cause a shock that lies closer to the vehicle with respect to the position that would characterize a perfect gas case. These effects obviously occur only at higher Mach numbers.

Further, regarding to the aerodynamic coefficients, it is well known that at very high altitude, when the Reynolds number decreases and rarefaction effects are present, there is a strong increase of the drag coefficient and a consequent reduction of the maximum efficiency. Another aspect that has to be considered is the interaction of the bow shock 
with the shock generated by the wing. It is an important phenomenon that has to be investigated because it can have a significant impact on the local pressure and heat flux distribution. As far as the laminar to turbulent transition is concerned, it is well known that it can cause strong overheating on the skin.

\section{Nomenclature}

$\begin{array}{ll}B: & \text { Wing span } \\ C_{D}: & \text { Drag coefficient } \\ C_{L}: & \text { Lift coefficient } \\ C_{\mathrm{My}}: & \text { Pitching moment coefficient } \\ D: & \text { Aerodynamic drag } \\ H: & \text { Enthalpy per unit mass } \\ L: & \text { Aerodynamic lift/Fuselage length/Chord length } \\ M: & \text { Mach number/Aerodynamic moment } \\ \dot{q}: & \text { Convective heat flux } \\ Q: & \text { Integrated heat load } \\ R: & \text { Radius of curvature } \\ \mathrm{Re}: & \text { Reynolds number } \\ \mathrm{Re} / m: & \text { Unit Reynolds number } \\ S: & \text { Reference area } \\ T: & \text { Temperature } \\ V: & \text { Velocity } \\ x: & \text { Distance along vehicle forebody running from nose. }\end{array}$

Greek Symbols

$\alpha$ : Angle of attack

$\Lambda$ : Leading edge sweep angle.

\section{Subscripts}

$\begin{array}{ll}B: & \text { Body } \\ \text { cyl: } & \text { Cylinder } \\ E: & \text { Entry } \\ \text { eff: } & \text { Effective } \\ \text { LE: } & \text { Leading edge } \\ \text { MRP: } & \text { Moment reference point } \\ N: & \text { Nose } \\ \text { ref: } & \text { Reference } \\ \text { sp: } & \text { Stagnation point } \\ w: & \text { Wing } \\ Y: & \text { Pitching moment } \\ 0: & \text { Total (reservoir) value } \\ \infty: & \text { Freestream conditions. }\end{array}$

Acronyms

AEDB: Aerodynamic Data Base

AoA: Angle of Attack

ATDB: Aerothermodynamic Database

BLM: Boundary Layer Method

BRF: Body Reference Frame

CFD: Computational Fluid Dynamic

CIRA: Centro Italiano Ricerche Aerospaziali

CMC: Ceramic Matrix Composites
CoG: Centre of Gravity

DRLS: Down Range Landing Site(s)

$\mathrm{Eff}=\mathrm{E}$ : Aerodynamic efficiency

FLPP: Future Launcher Preparatory Programme

LEO: Low Earth Orbit

MECO: Main Engine Cut Off

SOH: Suborbital Hopper

SSI: $\quad$ Shock-Shock Interaction

TAEM: Terminal Area Energy Management

TPM/S: Thermal Protection Material/System

VTO: Vertical Take-Off Hopper.

\section{References}

[1] C. Tomatis, L. Bouaziz, T. Franck, and J. Kauffmann, "RLV candidates for European Future Launchers Preparatory Programme," in AIAA 57th International Astronautical Congress (IAC '06), pp. 7430-7437, October 2006.

[2] J. Kauffmann, "Future European launch systems in the FLPP overview and objectives," in AIAA 57th International Astronautical Congress, IAC 2006, pp. 7618-7623, October 2006.

[3] D. Olynick, "Trajectory-based thermal protection system sizing for an X-33 winged vehicle concept," Journal of Spacecraft and Rockets, vol. 35, no. 3, pp. 249-257, 1998.

[4] D. K. Prabhu, "System design constraints-trajectory aerothermal environments," in Critical Technologies for Hypersonic Vehicle Development, RTO AVT/VKI Lecture Series, Von Karman Institute for Fluid Dynamics, Rhode Saint Genèse, Belgium, 2004.

[5] S. Guédron, Y. Prel, C. Bonnal, and I. Rojo, "RLV concepts and experimental vehicle system studies: current statuse," in Proceedings of the 54th International Astronautical Congress of the International Astronautical Federation, Bremen, Germany, October 2003.

[6] J. J. Bertin, Hypersonic Aerothermodynamics, AIAA Educational Series, Washington, DC, USA, 1994.

[7] L. Gong, W. L. Ko, and R. D. Quinn, "Thermal response of space shuttle wing during reentry heating," in Proceedings of the 19th Thermophysics Conference, June 1984.

[8] B. Behrens and M. Müller, "Technologies for thermal protection systems applied on reusable launcher," in Proceedings of the 54th International Astronautical Congress of the International Astronautical Federation (IAF '03), pp. 619-626, October 2003.

[9] G. Pezzella, M. Marini, P. Roncioni, J. Kauffmann, and C. Tomatis, "Preliminary design of vertical takeoff hopper concept of future launchers preparatory program," Journal of Spacecraft and Rockets, vol. 46, no. 4, pp. 788-799, 2009. 

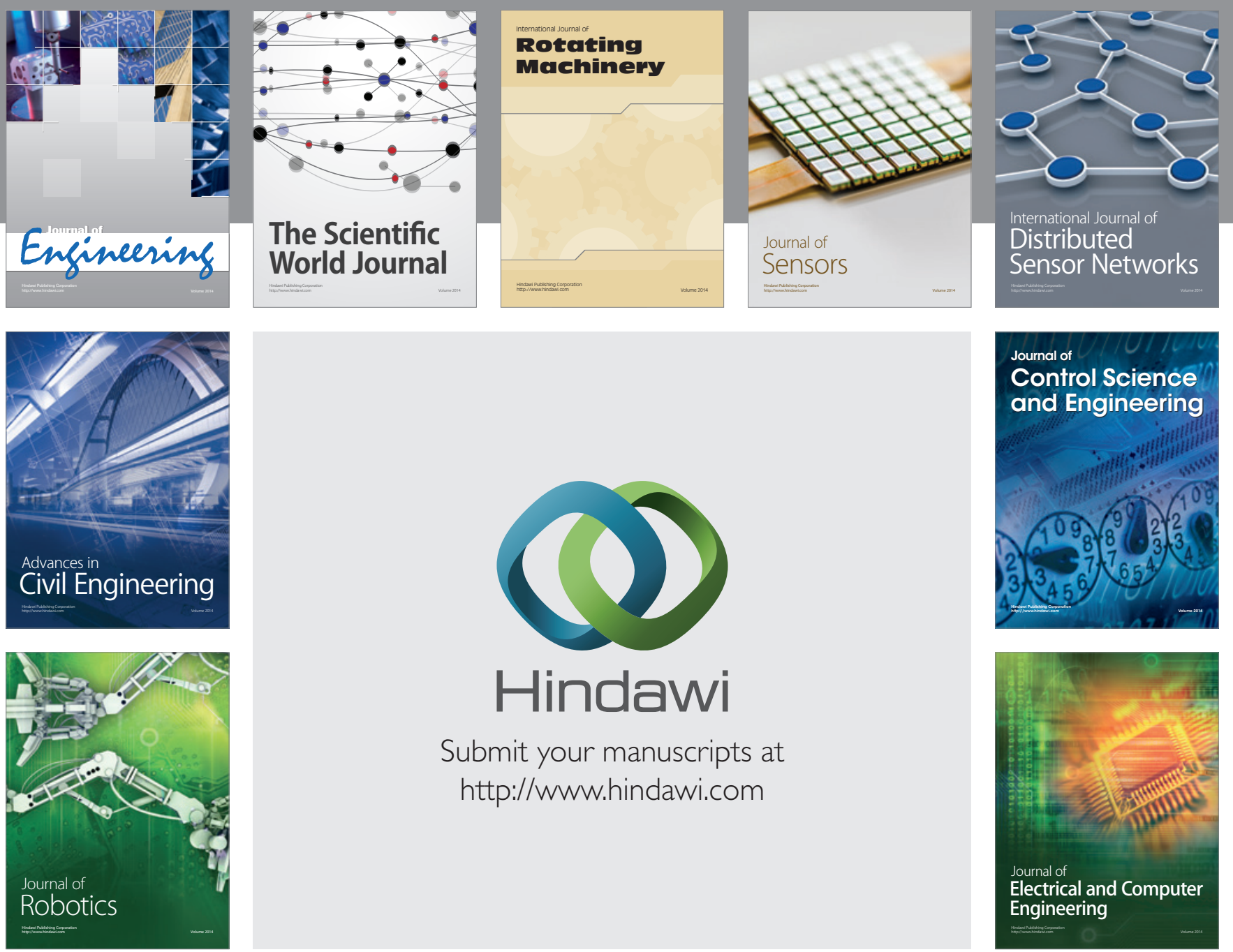

Submit your manuscripts at

http://www.hindawi.com
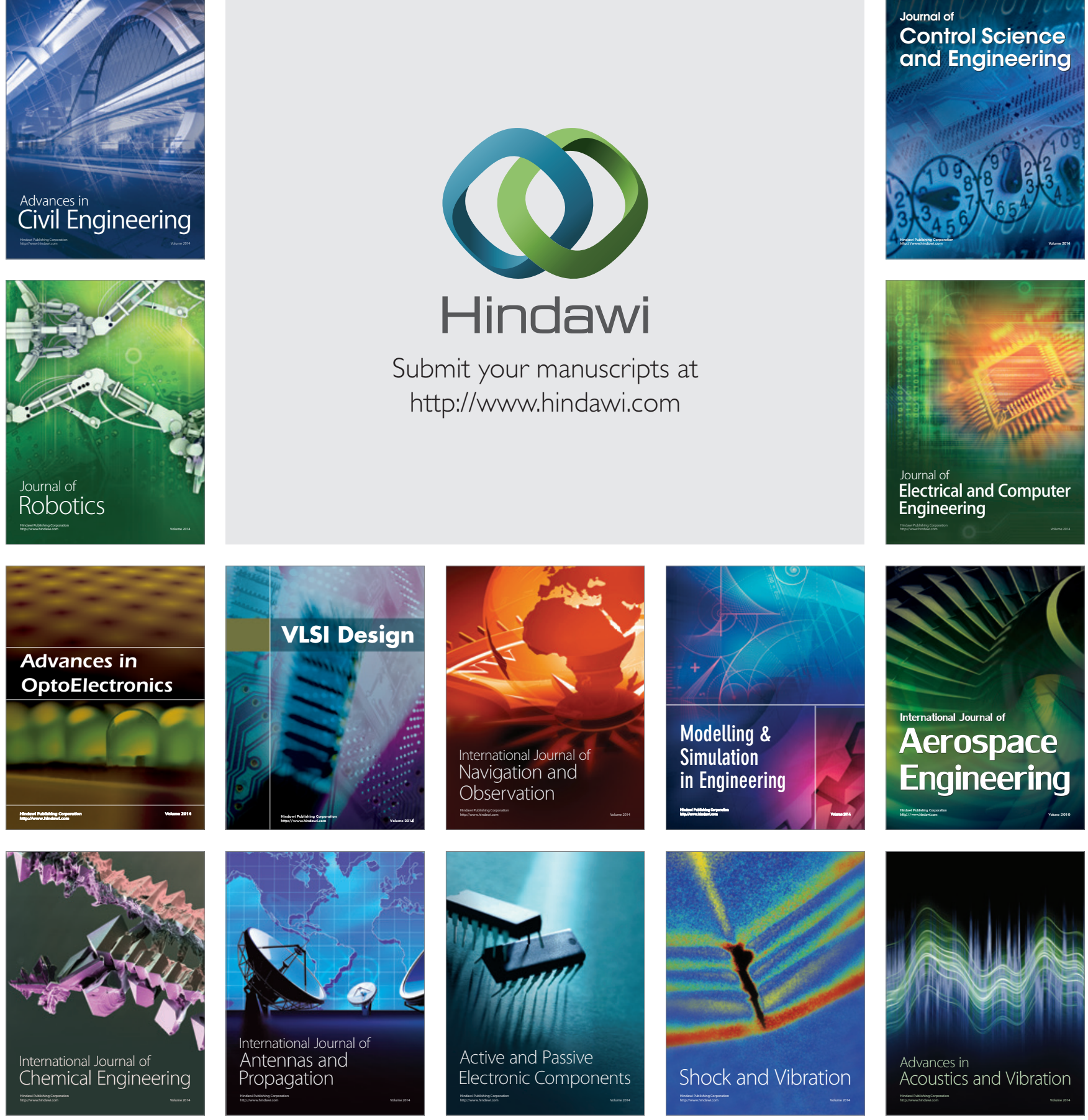